\title{
Refractive-index and density matching in concentrated particle suspensions: a review
}

\author{
Sébastien Wiederseiner • Nicolas Andreini • \\ Gaël Epely-Chauvin · Christophe Ancey
}

Received: 8 July 2010/Revised: 28 September 2010/Accepted: 15 October 2010/Published online: 5 November 2010

(C) Springer-Verlag 2010

\begin{abstract}
Optical measurement techniques such as particle image velocimetry (PIV) and laser Doppler velocimetry (LDV) are now routinely used in experimental fluid mechanics to investigate pure fluids or dilute suspensions. For highly concentrated particle suspensions, material turbidity has long been a substantial impediment to these techniques, which explains why they have been scarcely used so far. A renewed interest has emerged with the development of specific methods combining the use of iso-index suspensions and imaging techniques. This review paper gives a broad overview of recent advances in visualization techniques suited to concentrated particle suspensions. In particular, we show how classic methods such as PIV, LDV, particle tracking velocimetry, and laser induced fluorescence can be adapted to deal with concentrated particle suspensions.
\end{abstract}

\section{Introduction}

A large number of flows involve suspensions of particles in fluids. Typical examples include gravity-driven geophysical flows such as snow avalanches, debris flows, turbidity currents, pyroclastic flows, etc. Industrial pastes such as drilling muds, concrete, cosmetic pastes, pharmaceutical pastes, composites or foodstuffs offer other examples of particulate

\footnotetext{
S. Wiederseiner $(\square) \cdot$ N. Andreini · G. Epely-Chauvin

C. Ancey

Laboratoire d'Hydraulique Environnementale,

Ecole Polytechnique Fédérale de Lausanne,

1015 Lausanne, Switzerland

e-mail: sebastien.wiederseiner@a3.epfl.ch
}

suspensions (Ancey 2007). Concentrated particle suspensions exhibit non-Newtonian rheological properties and, over the last few years, a great deal of work has been done to understand their flow behavior. First attempts to model particle suspension date back to the beginning of the last century with the work of Einstein $(1906,1911)$. Since that time, a large body of work has been done in this field, with substantial theoretical, numerical, and experimental developments. A short and recent summary of the state of art can be found in the review paper by Mewis and Wagner (2009), but given the wide spectrum of topics in line with the dynamics of suspensions, there is no comprehensive review of this growing field. Despite many rheometric investigations into the rheology of concentrated particle suspension, many questions have as yet received little answers. Experimental studies of these materials are faced with measurement problems that make the results difficult to analyze and understand. All usual difficulties encountered in rheometry such as bottom-end effects, sample rupture (especially at high particle fraction), free surface deformation and flow instabilities are amplified, with little ways of alleviating their disturbing effects. Additional effects arise with concentrated suspensions: wall slip [due mainly to particle depletion at the wall (Barnes 1995; Jana et al. 1995), shear localization (Ancey and Coussot 1999; Coussot 2005), particle migration/segregation (Abott et al. 1991), and the finite-size limit when classic narrow-gap Couette cells are used (Ancey 2005)].

There has been a significant change of perception in the experimental study of concentrated particle suspensions over the last two decades. Until the late 1980s, most of the knowledge stemmed from macroscopic measurements obtained by using classic rheometers and viscometry theory (Walters 1975). Indeed, according to this theory, the flow curve (i.e., the relation between the shear 
stress $\tau$ and shear rate $\dot{\gamma}$ ) can be derived from bulk measurements (i.e., torque and rotational velocity in classic rheometers) by solving an inverse problem. While performing well for most fluids of practical interest, viscometry theory runs into difficulties with complex fluids, since many of the assumptions needed to solve the inverse problem (such as fluid homogeneity and the existence of a one-to-one relation between stress and rate of strain) are no longer valid. In the last 20 years, a new trend has emerged, with emphasis given to visualization techniques to derive the flow curve directly. For instance, sophisticated tools such as Magnetic Resonance Imaging (MRI) are now increasingly used to visualize flow behavior inside a rheometer (Bonn et al. 2008; Coussot et al. 2003; Ovarlez et al. 2006). The reader is referred to the review papers of Callaghan (1999), Elkins and Alley (2007) and Fukushima (1999) to get a better idea of the potential of MRI techniques in fluid mechanics. These wonderful techniques are, however, not free of problems. For instance, their spatial and temporal resolutions are often not high enough when studying complex suspensions with time-dependent response. Furthermore, they also involve heavy procedures and expensive tools that make them hardly versatile and user-friendly. In a few investigations on concentrated particle suspensions, Acoustic doppler velocimetry (ADV) has also been used to measure velocity profiles (Ouriev 2000, 2002). As this technique is still in the early stages of development for concentrated particle suspensions, we lack perspective concerning these techniques.

Another approach involves using image-processing techniques to visualize what occurs inside the flow. A major impediment arises, however, with most fluids since they are opaque. With particle suspensions, it is sometimes possible to get round this issue by matching the refractive index of both the solid and liquid components to obtain a transparent suspension. While the principle is straightforward, its implementation is far less simple. Once this has been achieved, classic optical techniques such as particle image velocimetry (PIV), particle tracking velocimetry (PTV), Laser Doppler Velocimetry (LDV) or Laser Induced Fluorescence (LIF) can be used (see "Appendix 1 " for references). There are many advantages of this approach over magnetic resonance imaging and nuclear magnetic resonance (NMR) techniques: reasonable cost, robustness and versatility of the techniques, greater accuracy. There are also drawbacks: transparent suspensions must be used and experiments are highly sensitive to temperature and humidity changes, which imposes a rigorous experimental protocol. As we shall see in the present work, a careful refractive index matching (RIM) procedure is the key to obtaining reliable measurements in concentrated particle suspensions.
In recent years, RIM techniques have undergone a tremendous development, with numerous applications in flow visualization (in engines, arteries, etc.), density currents in tanks, porous media, and more recently concentrated suspensions. With the wealth of ideas and special methods developed in this growing field, it is difficult to draw the boundaries of RIM-based visualization techniques with any confidence; in particular, the newcomer to the field gets quickly lost in the abundance of details and recipes that can be found in the technical literature, while at the same time, there is no comprehensive monograph that provides guidance on these techniques. In addition, while RIM-based methods are reasonably simple to use in visualization problems in which there are only a few fluid-solid and solid-fluid interfaces through which one would like to see, they become much more demanding when the number of interfaces increases significantly. For instance, if we take a $10 \mathrm{~cm}$ thick sample made up of 1-mm particles, there are at least 200 interfaces to cross if we want to see through the sample. The point is that each interface introduces slight mismatches in the refractive index, which cumulate and eventually cause image deformation that affects flow measurement. For this reason, there is a maximal distance in multi-interface materials, above which no measurement is possible. For many applications, increasing this limiting distance is of great importance.

This paper is a first stab at reviewing RIM techniques. The main objective is to show how refractive-indexmatching techniques can be used to visualize what occurs in concentrated particle suspensions. A second objective is to address visualization problems of particular relevance to multi-interface systems such as particle suspensions. Indeed, while RIM techniques are not new, their use in complex systems characterized by numerous optical interfaces is made difficult unless optimal matching in the refractive index is achieved. Our intent is thus not only to review some techniques that makes this optimal matching possible, but also to provide practical information such as couples of fluids and materials that are well suited to this purpose.

The paper is divided into two parts. The first part is devoted to the presentation of the techniques. After a short summary of applications (see Sect. 2), we outline the refractive-index-matching techniques that are well suited to preparing transparent concentrated particle suspensions in Sect. 3 We confine attention to specific flow visualization techniques based on tracers in Sect. 4 The second part of the paper describes some examples of application that stem from a set of experiments we have conducted in recent years. After many trials and errors, we managed to find appropriate materials (see Sect. 5) and to work out highquality matching techniques (see Sect. 6) for highly concentrated suspensions. We illustrate these techniques 
through the Couette-cell experiment (in which a concentrated particle suspension is poured into the gap separating two rotating cylinders). The goal of this experiment was to derive the flow curve $\tau(\dot{\gamma})$ by differentiating the velocity profile across the gap, which can be measured using RIM techniques. In Sect. 7, we show on this particular example how particles were tagged to be tracked by a camera, while Sect. 8 presents the final results.

\section{Examples of application}

RIM techniques are relatively old, with the first applications dating back to the 1950s. It was however not until the late 1980s that the experimental protocol was more formally established with the seminal papers of Nouri et al. (1988) and Koh (1991). Since then, several authors have elaborated on the refraction technique worked out by Nouri et al. (1988). Here, we provide some typical applications over the last 50 years, which can help the reader to contextualize the techniques with respect to applications.

\subsection{Fluidized beds and particle suspensions}

As far as we know, RIM techniques were first used to investigate fluidized beds of concentrated noncolloidal particle suspensions (Handley 1957). Abbas and Crowe (1987) and Karnis et al. (1966) studied the flow properties of a homogeneous slurry and Chen and Fan (1992) the flow three-dimensional structure. Ackerson and Pusey (1988) looked at particle ordering. Breedveld et al. (1998, 2001a, b, 2002) and Leighton and Acrivos (1987) studied selfdiffusion in particle suspensions and Graham and Bird (1984) particle clustering. Ham and Homsy (1988), Kapoor and Acrivos (1995) and Nicolai et al. (1995, 1996) examined settling suspensions. Jana et al. (1995) observed wall slip effects for concentrated suspensions. Kohnen and Bohnet (2001) considered the suspension flow in an agitated vessel. Lenoble et al. (2005a) and Wiederseiner (2010) measured the velocity profiles in a rheometer (in a parallel-plate and a wide-gap Couette cell, respectively). Averbakh et al. (1997), Koh et al. (1994), Lyon and Leal (1998a, b), Park et al. (1989), Shauly et al. (1997), and Zisselmar and Molerus (1979) observed the flow of concentrated slurries in pipes. Wildman et al. (1992) looked at pipe contraction flows. Chen et al. (2005) and Mikami et al. (2001) studied natural flow convection in particle suspensions. Colloidal suspensions were also studied by Chaudhuri et al. (2008), Dibble et al. (2006), Gao and Kilfoil (2007), Kaufman and Weitz (2006), Kegel and van Blaaderen (2000) and Weeks et al. (2000).

\subsection{Porous media}

RIM techniques have also been abundantly used to investigate fluid flows through porous media or closely packed beds. Typical examples include the works of Cenedese and Viotti (1996), Hassan and Dominguez-Ontiveros (2008), Johnston et al. (1975), Kubo et al. (1978), Montemagno and Gray (1995), Moroni and Cushman (2001), Northrup et al. (1991a, b, 1993), Okumura et al. (2005), Peurrung et al. (1995), Rashidi et al. (1996), Saleh et al. (1992), Stephenson and Stewart (1986), Stöhr et al. (2003), and Yarlagadda and Yoganathan (1989).

\subsection{Flows through complex geometries}

RIM techniques make it possible to use classic optical measurement methods in complex and curved geometries. For instance, Varty (1984) and Zerai et al. (2005) used RIM fluids to better understand fluid flow into heat exchangers. Uzol et al. (2002) examined the flow near the blades of a turbo-pump with a rotor, stator, and blades made up of polymethylmetacrylate (PMMA). Bovendeerd et al. (1987), Durst et al. (1988), Jacobs et al. (1988), and Parker and Merati (1996) were able to look through curved walls such as circular pipes or Couette cells. Liu et al. (1990) visualized the coolant passages of an internal combustion engine. Hopkins et al. (2000) characterized the flow into an optically transparent nasal cavity and Budwig (1994), Gijsen et al. (1996) and Nguyen et al. (2004) the flow in arteries. Alahyari and Longmire (1994), Atsavapranee and Gharib (1997), Augier et al. (2003), Daviero et al. (2001), Hannoun et al. (1988) and McDougall (1979) used two sets of immiscible refractive-index-matched fluids to measure into density-stratified flows.

\section{Refractive index matching}

Optical visualization into concentrated particle suspensions calls for convenient methods for matching the fluid and particle indices of refraction. In principle, the more accurate this matching is, the higher visibility is within the suspension. There are, however, numerous impediments to high visibility: as a result of the manufacturing process, particles may not have the same index of refraction; impurities in the particles or in the fluid (e.g., gas bubble) reduce the field of visibility; temperature gradients within the suspension also alter this field. As a consequence, the first step - and perhaps the most important-is to select particles with excellent optical properties (constant index of refraction, few impurities, etc.). Needless to say that with particles of insufficient quality, the particle suspension remains opaque even with the "best" matched fluid (see for 
Fig. 1 Optical quality of the beads: a particles with good optical properties, b slightly opaque particles with gas bubble inclusions
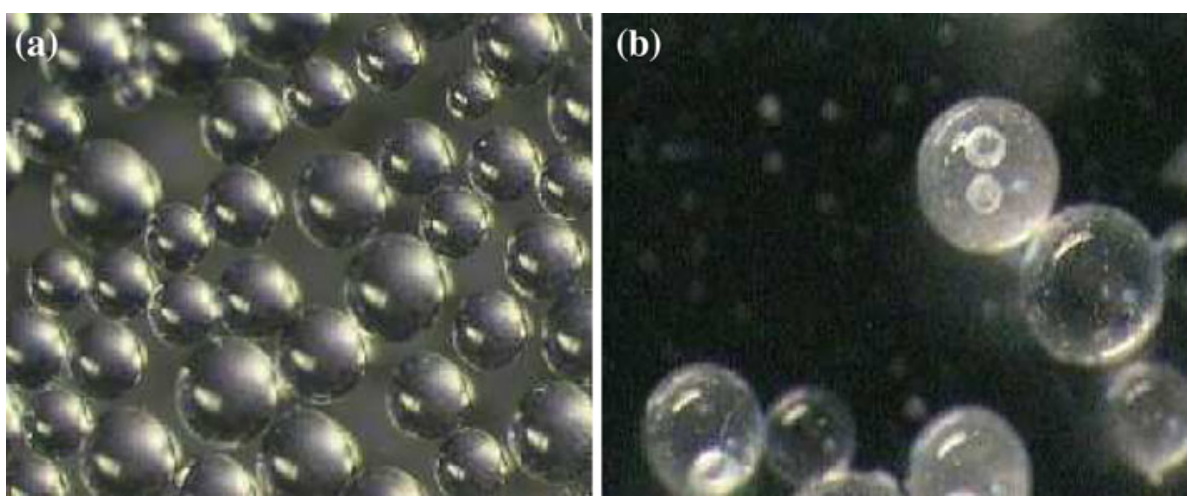

example Fig. 1). Here, we outline RIM techniques that are well suited to multi-interface systems.

\subsection{Index-matching material for concentrated particle suspensions}

For particles, we must select transparent materials. This includes plastics, glass, and certain synthetic rubbers. Nylon, polycarbonate (PC), polyetheretherketone (PEEK), polyethyleneterephthalate (PET), polystyrene (PS), polyvinylchloride (PVC), styrene/acrylonitrile copolymer (SAN) and glasses are mostly excluded because they exhibit too high refractive indices. Indeed the latter (hereafter referred to as $n_{D}$ ) often exceeds 1.5 , as shown in Table 1 , which would require liquids with refractive indices above 1.580. Such liquids are rare, and most of them are toxic. Some examples are Aniline $\left(n_{D}=1.586\right)$, Bromoform $\left(n_{D}=1.590\right)$, Iodobenzene $\left(n_{D}=1.620\right)$, Quinoline $\left(n_{D}=1.620\right)$, and Carbon disulfide $\left(n_{D}=1.625\right)$. Some potential candidates are merely too expensive.

Many plastics (refractive index within the 1.37-1.50 range) are transparent if they are free of fillers or other impurities and provided that they are in the amorphous state or have a crystalline structure smaller than the wavelength of the light incident upon the plastic. Among synthetic rubbers only silicone rubber $\left(n_{D}=1.42\right)$ is transparent. Only a few plastics (polymethylmethacrylate, polytetrafluoroethylene, fluorinated ethylene-propylene, tetrafluoroethylene) are manufactured industrially in the transparent (amorphous) form. Crystalline polymers can be made transparent by heating above the "melting temperature", at which there is a transition to the amorphous state, followed by rapid quenching to room temperature. The plastics listed in Table 2 have refractive indices lower than 1.49 in the amorphous state. There are many possible fluid mixtures to achieve index matching for $n_{D}<1.49$. In this case, mixture toxicity depends on the fluids used for RIM. Appendix 2 gives a non-exhaustive list of fluids that have been used in the literature.
Table 1 Possible RIM candidates with high-index fluids

\begin{tabular}{lll}
\hline & RI & $\begin{array}{l}\text { Melting temp. } \\
\left({ }^{\circ} \mathrm{C}\right)\end{array}$ \\
\hline Nylon 6,6 & 1.565 & 255 \\
Polycarbonate (PC) & 1.586 & 267 \\
Polyetheretherketone (PEEK) & $1.65-1.77$ & 334 \\
Polyethyleneterephthalate (PET) & 1.575 & 68 \\
Polystyrene (PS) & 1.59 & 100 \\
Polyvinylchloride (PVC) & 1.54 & 80 \\
Styrene/acrylonitrile copolymer & 1.57 & 100 \\
$\quad$ (SAN) & & \\
\hline
\end{tabular}

Table 2 Possible RIM candidates with low-index fluids

\begin{tabular}{lll}
\hline & RI & Melting temp. $\left({ }^{\circ} \mathrm{C}\right)$ \\
\hline $\begin{array}{l}\text { Fluorinated ethylene-propylene } \\
\quad \text { FEP) }\end{array}$ & 1.34 & 340 \\
Fused quartz & 1.458 & 1,650 \\
Glass & $1.47-1.65$ & $500-1,100$ \\
Polychlorotrifluoroethylene (PCTFE) & 1.435 & 216 \\
Polyformaldehyde (POM) & 1.41 & $175-180$ \\
Polymethylmethacrylate (PMMA) & 1.49 & $130-140$ \\
Polysiloxane (Silicone rubber) & 1.40 & 300 \\
Polytetrafluoroethylene (PTFE) & 1.38 & 327 \\
Polyvinylacetate (PVA) & 1.466 & 230 \\
Silica gel & 1.472 & 1,610 \\
Tetrafluoroethylene (TFE) & 1.34 & - \\
\hline
\end{tabular}

For the interstitial fluid, we have often to mix different components to obtain a solution with the desired index of refraction, viscosity, and density. Additional criteria are also important:

- optical quality of both the fluid and beads should be checked carefully: the index of refraction must stay constant, fluid absorption must be negligible, materials must not be spoiled with impurities and inclusions;

- the particles' surface may be tagged by fluorescent dyes and in this case, it should be checked that the state of 
surface is compatible with the dye and interstitial fluid(s);

- the fluid needs to wet the beads, it should neither adulterate or dissolve the beads' surface;

- volatile fluids should be avoided;

- the material making up the particles or the fluid should be as neutral as possible when lightened by the laser (e.g., it should not be excited by the laser over the wavelength range over which it is operated).

\subsection{Refractive index mixture rules}

It is often desirable to determine the index of refraction of a solute. This index can be estimated from the refractive indices of solution and solvent by using a suitable "mixture rule". There are several available methods in the literature (see for example Aminabhavi 1984; Heller 1965; Shindo and Kusano 1979 or Tasic et al. 1992 for an overview). All theoretically derived rules are based upon the electromagnetic theory of light and can apply only if there is no change of volume during mixing. The most classic equations include

- Lorentz-Lorenz equation (Lorentz 1906):

$\frac{n_{12}-1}{\left(n_{12}^{2}+2\right) \rho_{12}}=\left(\frac{n_{1}^{2}-1}{n_{1}^{2}+2}\right) \frac{p_{1}}{\rho_{1}}+\left(\frac{n_{2}^{2}-1}{n_{2}^{2}+2}\right) \frac{p_{2}}{\rho_{2}}$

- Wiener equation (Wiener 1910):

$\frac{n_{12}^{2}-n_{1}^{2}}{n_{12}^{2}+2 n_{1}^{2}}=\phi_{2} \frac{n_{2}^{2}-n_{1}^{2}}{n_{2}^{2}+2 n_{1}^{2}}$

- Heller equation (Heller 1945):

$\frac{n_{12}-n_{1}}{n_{1}}=\frac{3}{2} \frac{m^{2}-1}{m^{2}+2}, \quad$ with $\quad m=\frac{n_{2}}{n_{1}}$

- Dale-Gladstone equation (Dale and Gladstone 1858, 1864):

$\frac{n_{12}-1}{\rho_{12}}=\frac{n_{1}-1}{\rho_{1}} p_{1}+\frac{n_{2}-1}{\rho_{2}} p_{2}$

- Arago-Biot equation (Arago and Biot 1806):

$n_{12}=\phi_{1} n_{1}+\phi_{2} n_{2}$

- Lichtenecker equation (Heller 1945):

$\ln n_{12}=\phi_{1} \ln n_{1}+\phi_{2} \ln n_{2}$

- Newton equation:

$n_{12}^{2}=\phi_{1} n_{1}^{2}+\phi_{2} n_{2}^{2}$

with $n_{i}(i=1,2)$ the index of refraction of either pure fluid, $n_{12}$ the mixture refractive index, $\phi_{i}(i=1,2)$ the component volume fraction in the mixture of either pure fluid, $p_{i}$ $(i=1,2)$ the component weight fraction in the mixture of either pure fluid, $\rho_{i}(i=1,2)$ the density of either pure fluid and $\rho_{12}$ the mixture density.

As we will see in Sects. 3.3 and 6, these mixture rules are very useful to the synthesis of a fluid at a prescribed index of refraction when the objective is to find a solution whose index of refraction matches that of the particles.

\subsection{Small particle index matching methods}

As far as we know, there is no method that makes it possible to measure the refractive index of small particles accurately and conveniently. Thus, it is not possible to first measure the refractive index of particles and then adjust the refractive index of the interstitial fluid by changing its composition so that it has the same index of refraction. Therefore, one has to measure it indirectly. There are two approaches to obtaining the particle index of refraction:

- By using a bulk solid sample and measuring the reflection (Budwig 1994) or refraction (Nouri et al. 1988) of a laser beam (Sect. 3.3.1) or by directly measuring the solid refractive index using a refractometer (Sect. 3.3.2).

- By measuring transmitted light through a suspension sample by varying either the sample temperature or the light wavelength (Sects. 3.3.3-3.3.5). Using this method requires good knowledge of the refractive index of particles because it allows precise matching over a very limited range of refractive indices. For this approach, all variants use the Christiansen effect (Christiansen 1884, 1885; Raman 1949).

In the following, we are going to review methods that have been used to match the refractive index of a solid compound with that of a fluid mixture.

\subsubsection{Bulk sample laser method}

Nouri et al. (1988) and Budwig (1994) proposed an ingenious way of matching the refractive index of their particles with that of the interstitial fluid. Nouri et al. (1988) used the refracted beam deviation to match the refractive index while Budwig (1994) used the reflected beam intensity instead. A laser beam is shined into a solution containing a large rod (refraction technique) or a flat plate (reflection technique) made up of the same material as the particles. The sample is placed in such a way that the reflected beam is just a few degrees away from backward reflection. By varying the composition of the solution (thus varying its index of refraction), the laser beam passing through the system is deviated with different degrees of deflection depending on the mismatch between the rod and 
the fluid. At the same time, the backward reflection intensity changes and is described by the following equation:

$R=\left(\frac{1-n_{l} / n_{s}}{1+n_{l} / n_{s}}\right)^{2}$,

where $R$ is the ratio of the reflected beam power to the incident beam power and $n_{l}, n_{s}$ are the liquid and solid refractive index, respectively.

This equation shows that, if the solid and fluid indices of refraction are perfectly matched $\left(n_{s}=n_{l}\right)$, the reflected beam should shut off. Because of imperfections and local variations in the refractive index, this is, however, never achieved in practice. Therefore, the point of best match is attained when the beam passes through the system without any deflection (Nouri et al. 1988) or when the monitored backward reflection of light on the immersed solid sample reaches a minimum value (Budwig 1994). The next and last step is to measure the fluid refractive index with a refractometer. Special attention has to be paid to temperature control and light wavelength. Indeed, in order to avoid disturbances resulting in the Christiansen effect (Christiansen 1884, 1885; Raman 1949), temperature must stay constant and light wavelength must be the same.

Figure 2 shows the apparatus used for refractive-index tuning for both the refraction and reflection techniques. For both methods, a bulk sample made up of the same material as the particles must be used. The index of refraction of the bulk sample must not be modified during the manufacturing process.

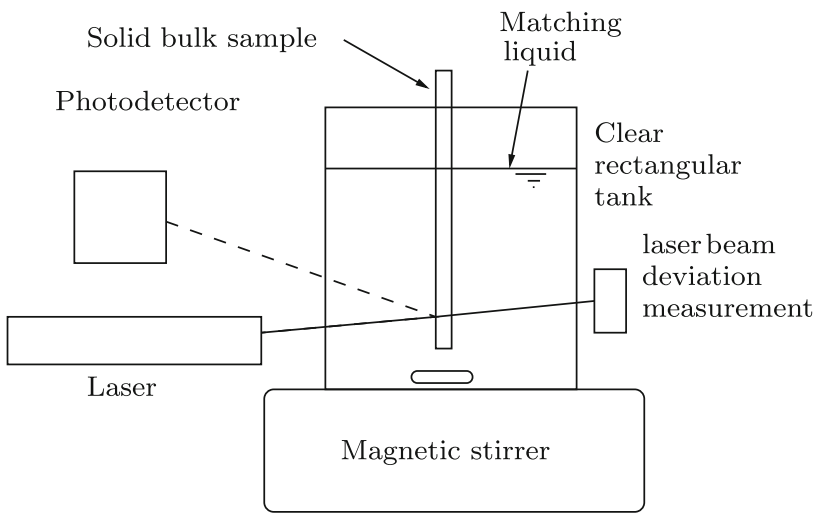

Fig. 2 In the backward reflection method (after Budwig 1994) and refracted beam deviation method (after Nouri et al. 1988), the laser beam reflection intensity is measured by a photodetector. The matching is achieved when the reflected beam intensity reached its minimum. Otherwise, the refracted laser beam deviation is measured after passing through the immersed solid sample. The best match is achieved when the laser beam is not deviated

\subsubsection{Bulk sample refractometer method}

Most refractometers can be used to measure the refractive index of a solid. A small sample of the solid with a flat polished surface is placed in optical contact with the refractometer prism. Optical contact is established by filling the gap between the prism and the sample with a liquid. The refractive index of the liquid $n_{l}$ must satisfy the constraint

$n_{\text {sample }}<n_{l}<n_{\text {prism }}$,

where $n_{\text {prism }}$ denotes the refractive index of the prism while $n_{\text {sample }}$ is the refractive index of the sample at hand. Refractometry of solids is described at length in Sinkankas (1966) and Hurlburt (1984). To use this method, one must have a bulk sample of the same material as that of the particles. Sample temperature as well as the light wavelength used for the measurement must be controlled accurately.

\subsubsection{Wavelength method}

This method was proposed by Stöhr et al. (2003). As a result of the differences in optical dispersion in each phase, the refractive indices can be matched for only one wavelength. Light with a different wavelength is refracted at the solid-liquid interfaces, with the angle of refraction increasing when the wavelength is moved away from the matching wavelength (Christiansen 1884, 1885). This phenomenon results in a transmittance curve with a maximum at the matched wavelength.

A light beam of a broadband lamp is used to enlighten a particle suspension. The transmitted light is then collected by a spectrophotometer. The refracted light has to be removed using a slit plate. Next a wavelength-light intensity curve can be drawn. It has to be normalized with the incoming light spectrum intensity. Once this curve has been obtained, one can deduce the refractive index of the particles by measuring the refractive index of the fluid at the wavelength corresponding to the maximum of transmittance. During this experiment, great care must be brought to keep the temperature constant because it influences the refractive index of the components. To guarantee homogeneity in the particle concentration, the suspension must be continually stirred during the matching experiments. Figure 3 shows a scheme of the experimental setup.

\subsubsection{Temperature method}

This approach was proposed by Koh (1991), Koh et al. (1994) and improved by Wiederseiner (2010). As for the wavelength method, we can match the refractive index only at a given temperature since the refractive indices of 


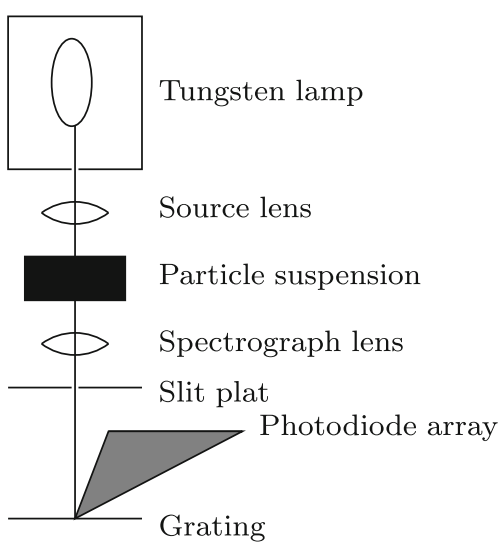

Fig. 3 The wavelength method (after Stöhr et al. 2003). A light beam of a broadband lamp is used to enlighten a particle suspension. The transmitted light is then collected by a spectrophotometer. A wavelength-light intensity curve can be drawn and the maximum gives the matched wavelength at which the suspension is RI-matched

the liquid phase and the solid phase depend differently on temperature.

A typical sketch of this method is given by Fig. 4. Shining a laser beam through a temperature-controlled suspension sample and recording the transmitted light results in a curve with a maximum at the matched temperature. To get rid of laser power fluctuations, a beam splitter is placed in front of the particle suspension. The deviated beam is used to continuously monitor the laser power fluctuations in time and avoid biased transmission curve due to power fluctuations. Half of the laser beam then passes through the particle suspension sample. The sample is temperature-controlled by two water-cooled plates. A Pt100, temperature probe is directly immersed in the sample to record the actual suspension temperature and alleviate most sample insulation problems. To ensure thermal homogeneity within the suspension, a magnetic stirrer is used during the whole experiments to mix the particle suspension. It also enhances the transmittance signal by changing the particle configuration in the region crossed by the transmitted laser beam. This allows reducing the effect of imperfections of particles or residual impurities in the suspension. A pinhole is placed in front of the transmittance powermeter to reduce scattered light effects as much as possible. At a given temperature, the normalized transmitted light intensity reaches a maximum. The refractive index of the fluid is measured at that temperature to obtain the refractive index of the beads.

\subsubsection{Scattered-light-shape-distribution method}

Averbakh et al. (1997) proposed another technique for the RIM procedure, which is closely related to the wavelength and temperature methods. To guarantee homogeneity in the particle concentration, the suspension must be continually stirred during the RIM experiments. A laser beam is shined through a vessel filled with the particle suspension. The shape distribution of the scattered light is then recorded on an array of photoreceivers. A set of apertures selects only the central scattered light and cuts off peripheral light noise. A neutral filter with variable optical density is put in front of the optical cavity. It is needed because the light intensity changes dramatically with particle concentration. Selecting the sharpest shape distribution of the scattered light allows determining the best possible refractive index for the fluid.

For RIM experiments, the refractive index of the fluid was changed in two ways by Averbakh et al. (1997) and
Fig. 4 The temperature method: based on the method proposed by Koh (1991), Koh et al. (1994) and improved by Wiederseiner (2010). A laser beam is shined through a temperature-controlled sample of suspension. As a result of the changes in the suspension temperature, the transmitted light is characterized by a curve with a maximum at the matched temperature

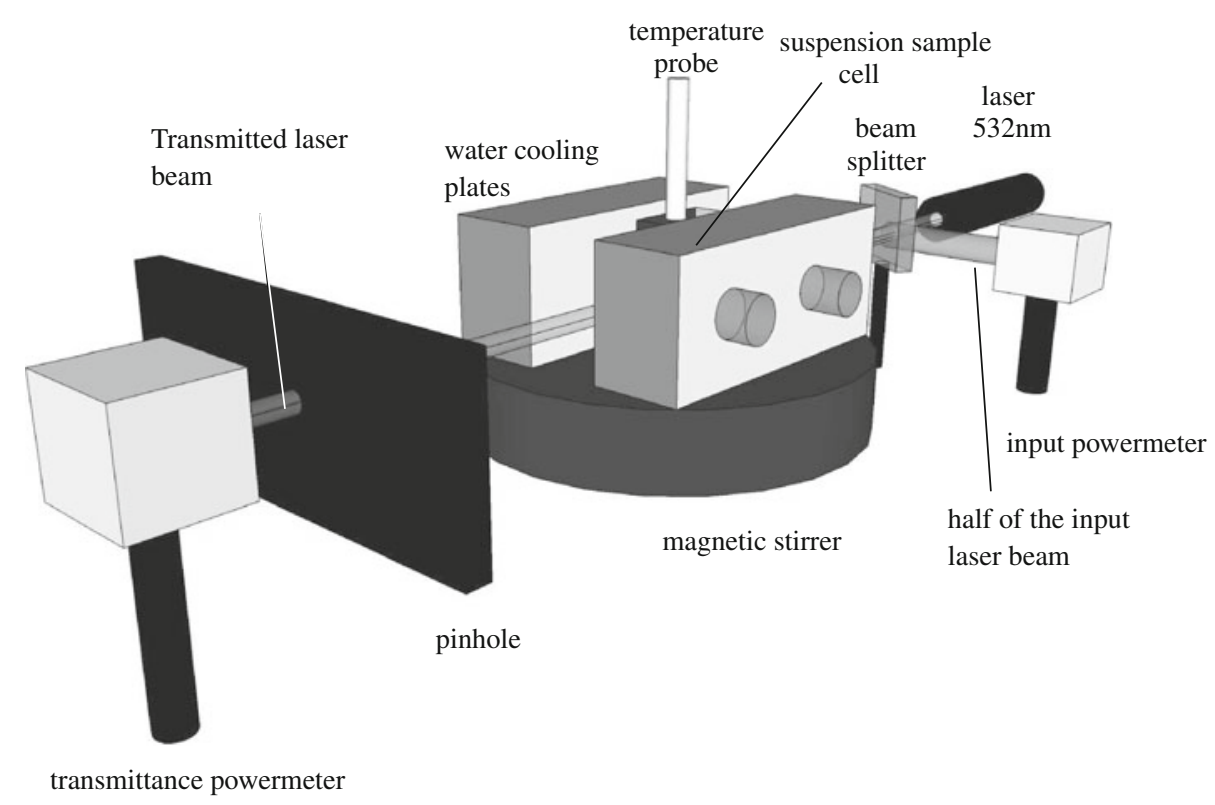




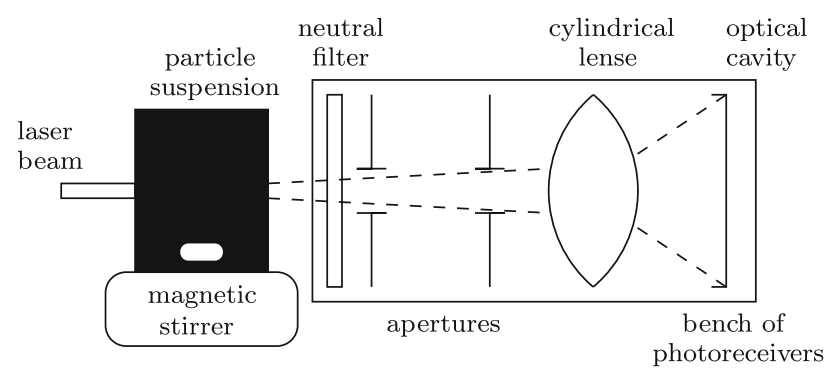

Fig. 5 The Scattered-light-shape-distribution method: based on the method proposed by Averbakh et al. (1997). A laser beam is shined through a vessel filled with a continuously stirred particle suspension. The shape distribution of the scattered light is then recorded on an array of photoreceivers

Shauly et al. (1997). First, these authors changed the fluid index of refraction by adding one component of the fluid and then they modified the refractive index by changing the suspension temperature similarly to the temperature method. Both techniques showed identical results near the matching point. Figure 5 shows a scheme of the experimental setup.

\section{Specific seeding of RIM flows}

As for classic measurements in single-phase flows, efficient seeding is the key parameter to good measurements in RImatched particle-suspension flows. However, once the best possible RIM suspension has been obtained, particles in the flow can no longer be seen neither they can be used as tracers directly. In this section, we will review the seeding possibilities for RIM particle suspensions.

\subsection{Foreign seeding particles}

As for standard PIV, PTV or LDV, foreign seeding particles scatter incoming light. The recording device (camera, photodetector) then records this signal. A great advantage of foreign seeding particles is that the choice of tracers is very wide, with almost all the possible desired properties available commercially. Typical examples include hollow glass spheres and silver-coated particles, which can be used to match fluid density and increase the scattered signal strength. The main drawback of this seeding lies in the seeding particles having the same size as the particles making up the suspension. Whereas in classic flow measurements, the tracers are assumed not to disturb the flow, which is essential to making the measurement technique non-invasive, this assumption does not hold true for particle suspensions. This is of particular significance to very concentrated particle suspensions, for which the rheologic behavior is influenced a great deal by the particle concentration. Furthermore, as the tracers cannot have the same mechanical properties as those making up the suspension (same size, density, roughness, shape, etc.), additional phenomena such as particle segregation may arise (Plantard et al. 2006) and if so, there is little hope that the tracers are really representative of the flow behavior.

\subsection{Fluorescent seeding particles}

Fluorescent seeding particles can be used as tracers in PIV and PTV within RIM suspensions (not LDV). An advantage over foreign seeding particles is the possibility to use the same particles (with almost the same physical properties, i.e. refractive index, density $\rho_{s}$, surface roughness, mean size, sphericity) as for the rest of the suspension. Using an appropriate optical filter allows rejecting the whole scattered laser light from the camera and in this way to enhance the signal-to-noise ratio. The main disadvantages include (i) a weaker light signal compared to tracers using light scattering and (ii) possible chemical incompatibilities between dye, particles, and RIM fluid mixture. Finally, because of the Stokes shift, the depth at which measurement can be taken is slightly reduced.

When the objective is to make some particles fluorescent, we need to tag particles with a fluorescent dye. Because of the added dye and sometimes of the tagging process, the tagged-particles properties change somehow. To maximize the amount of fluorescent light arriving at the recording device and, as a result, to exploit a large part of its dynamic intensity range, one would be tempted to increase the dye concentration as much as possible until saturation is reached. At the same time, concentration must be kept as low as possible to keep the refractive index of the tagged particles in a reasonable range. Therefore, a right balance has to be found depending on the particles, the fluorescent dye, its quantum efficiency, and the measurement setup (camera, lens, laser power, actual area-of-interest, etc.). An example can be found in Sect. 7 The onset of fluorescence lies in the picosecond range, while the light emission duration $(99 \%$ decay) is typically between 0.5 and $20 \mathrm{~ns}$. It is therefore suitable to PIV in liquid flow measurements, because these delays and durations lead to negligible errors over the time span $\Delta t$ between images. The fluorescent dye must be chosen with its maximum absorption close to the used laser line and with the highest possible efficiency. However, it must be selected with an emission spectrum as close as possible to the laser line because the suspension can only be matched at a single wavelength (Christiansen effect, see Sect. 3) The suspension becomes more turbid farther away form the laser line if it is perfectly matched at that wavelength. When needed, different dyes can be used simultaneously for tagging different particle species and they can be differentiated using appropriate optical filters. In practice, the farther the 
emission is from the matched wavelength, the shallower the depth (at which measurements can be performed) is.

An important characteristic of tracer particles is their stability inside the index-matched material. A severe problem may arise if the dye leaks out of the tracers and dissolve into the immersion fluid. The amount of unwanted dissolution critically depends on the nature and structure of the fluid. While dissolution of an ionic dye molecule is expectably negligible in non-polar hydrophobic fluids, it may turn considerable in water-based and surface-active solutions.

\subsection{Included tracers}

The third type of tracers are neither seeding particles, nor tagged particles. These tracers are integrated in the particles of the suspension (see Fig. 1b): they are impurities inside the suspension particles. They are mostly small gas bubbles trapped during the manufacturing process. The first advantage of these tracers is simplicity. There is no need to add tracers, tagged markers, or use optical filters. There is, however, a price to pay: we cannot take advantage of the possibilities offered by different dye emission wavelengths. These tracers just scatter the incident laser light. Unfortunately as these tracers are spoiled particles, there is usually no means to control the seeding (tracers' size, size distribution, proportion, etc.). Furthermore, as they may have slightly different physical properties (e.g., bulk density), their representativeness may be questionable.

\subsection{Tracking the fluid}

Finally, especially for particle concentration measurement based on LIF techniques, there is an alternative to tagging the particles: the liquid phase of the suspension can be tagged with fluorescent dye, which makes it possible to have a stronger light intensity signal in the most dilute regions and a weaker one in the most concentrated regions. This technique enables us to obtain concentration measurements, but is not suitable to velocity field measurements.

\section{Materials}

In this second part, we provide a full featured example. We conducted experiments with a Couette cell, i.e., a coaxial cylinder rheometer, whose gap was filled with a very concentrated suspension made up of coarse non-buoyant particles. Our objective was to measure the velocity profile within the suspension. As mentioned in the introduction, this velocity profile can be used to infer the flow curve, i.e. the relation between the shear stress and shear rate. In the sections thereafter, we explain at length how we proceeded. Our protocol is the fruit of many investigations, in which after many trials and errors, we tried to achieve high accuracy and reproducibility.

\subsection{Particle description}

The particles selected were copolymers of polymethylmethacrylate ethylacrylate (PMMA-EA) particles, manufactured by Arkema. To avoid segregation problems that arise with poorly sorted particles, we used only particles in the 180-200 $\mu \mathrm{m}$ size range. To that end, we followed the wet sieving procedure explained in detail in Wiederseiner (2010). We chose particles in this size range for three reasons. First, these particles had the greatest clarity in the laser-transmission experiments. Second, they were also characterized by good sphericity and they were in the peak of the particle size distribution of the raw material. Third, being produced industrially, these particles are relatively inexpensive. The particles used in our experiments came from a single batch.

\subsection{Fluid description}

To match the refractive index and the density of the particles at the same time, we had to use a mixture with at least three components (called trimix thereafter). The fluid mixture composition was described by Lyon and Leal (1998a, b). We adapted it to our particles. A non-exhaustive list of refractive-index-matching fluids used in the literature can be found in "Appendix 2".

The particle density and refractive index were matched by a fluid mixture with mass fractions of about $50 \%$ Triton $\mathrm{X} 100,28 \% \mathrm{DBH}$, and $22 \% \mathrm{UCON}$ oil. Each of these components provided a different feature of the mixture. Triton X100 has a high refractive index, DBH has a high density, and by using different UCON oils, we could adapt the fluid viscosity within a relatively wide range. The final mixture density is $1.184 \pm 0.0005 \mathrm{~g} / \mathrm{cm}^{3}$, the refractive index at $532 \mathrm{~nm}$ and $20^{\circ} \mathrm{C}$ is $1.48847 \pm 0.0001$, and its viscosity is $0.124 \pm 0.0025 \mathrm{~Pa}$ s at $20^{\circ} \mathrm{C}$.

\subsection{Density matching procedure}

When matching the fluid and particle densities, the crux lies in the particle density measurement. A density gradient column can be used to that end (Brown et al. 1996; Coombs 1981; Oster and Yamamoto 1963; Tung 1956; Tung and Taylor 1955, 1956), but less expensive techniques are also available. For our experiments, the matching method involved (i) mixing different fluids with a 

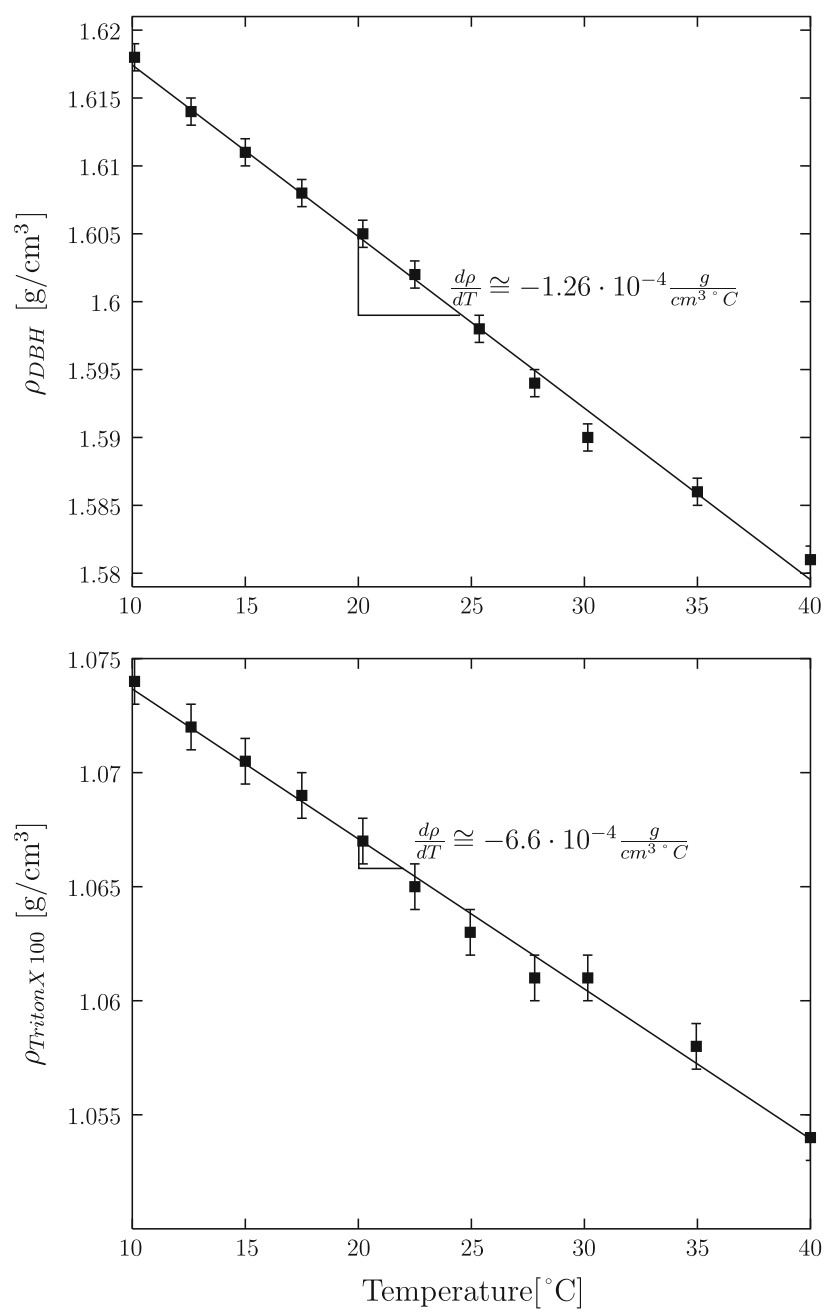

Fig. 6 Density variation of DBH and Triton X100 with temperature

density range close to the PMMA datasheet values and (ii) observing the time needed for the particles to rise or sink. The mixture where the particles remained in suspension the longest gave an estimate of the particle density. The densities of the fluid mixtures were estimated as the averages of the component densities weighted by the volume fractions of the components in the mixture. When a mixture was prepared in this way on the basis of the datasheet's densities of the fluids, a measurement of the true mixture density was performed with a high-precision aerometer (GECO-GERING, 0209 Aerometer DIN 12791 Serie L50, without Therm., Kl. "H", precision of $5 \times 10^{-4} \mathrm{~g} / \mathrm{cm}^{3}$ ) in a temperature-controlled column at $20^{\circ} \mathrm{C}$ because of the density variation of the fluid with temperature (see for example Fig. 6).

We prepared fluids with densities ranging from 1.1800 to $1.1865 \mathrm{~g} / \mathrm{cm}^{3}$ by step of $5 \times 10^{-4} \mathrm{~g} / \mathrm{cm}^{3}$. Because of the possible small variations in the particle density, we prepared particle-suspension samples with a solid fraction of
0.3 in sealed small bottles with a fluid height of $3 \mathrm{~cm}$ (i.e. on the same order as the depth of the Couette cell for our experiments). Using a suspension of particles allowed us to infer the mean particle density, but because of the Boycott effect and of the reduced sedimentation velocity in "dense" (approximately $\phi>0.2$ ) suspensions, the effective sedimentation velocity was lower than the single particle velocity at low Reynolds number (Davis and Acrivos 1985):

$V_{\infty}=\frac{1}{18} \frac{\left(\rho_{p}-\rho_{f}\right) g d_{p}^{2}}{\eta}$

with $V_{\infty}$, the terminal sedimentation velocity of an isolated particle, $\rho_{p}$ the particle density, $\rho_{f}$ the fluid density, $d_{p}$ the particle diameter, and $\eta$ the fluid viscosity. In an ideal geometry, the theoretical velocity of a suspension is (Guyon et al. 2001):

$V_{\text {sedim }}=V_{\infty}(1-6.55 \phi)$.

This expression results from a first-order expansion of the sedimentation velocity as a function of the solid concentration $\phi$ when two-particle interactions are taken into account. In practice, this velocity depends on the container features. For example in a spherical vessel, this velocity becomes:

$V_{\text {sedim }}=V_{\infty}(1-3.55 \phi)$.

It was therefore not possible to a posteriori calculate the density mismatch from the sedimentation velocity. We could, however, obtain an upper bound (the terminal velocity of a single particle). The bottles were immersed in a thermal bath $\left(20 \pm 0.05^{\circ} \mathrm{C}\right)$ for one week. Particle migration (causing particles to rise or sink) was monitored on a regular basis. In the best-matched fluid, we could not see any sedimentation effect after a one-week experiment. Taking a fluid sedimentation of $1 \mathrm{~cm} / \mathrm{week}$ (this is faster than what we could observe) and using the terminal velocity of an isolated particle, we can infer that the density mismatch was below $10^{-4} \mathrm{~g} / \mathrm{cm}^{3}$. This value was below the measurement uncertainties of the fluid density $\left(5 \times 10^{-4} \mathrm{~g} / \mathrm{cm}^{3}\right)$ when the uncertainties in the temperature control $\left( \pm 0.05^{\circ} \mathrm{C}\right)$ were taken into account. As the Couette cell and the sedimentation vessel had similar dimensions, we concluded from this experiment that sedimentation did not disturb our experiments even though they lasted a few days. Figure 7 shows the particle-suspension-sedimentation experiment after one week. The final density of the matching mixture was $1.1840 \pm 5 \times 10^{-4} \mathrm{~g} / \mathrm{cm}^{3}$; the uncertainty results from various processes (e.g., the density fluctuations of the beads within the batch provided by our supplier, errors in the temperature control, errors in the fluid-density measurements). 


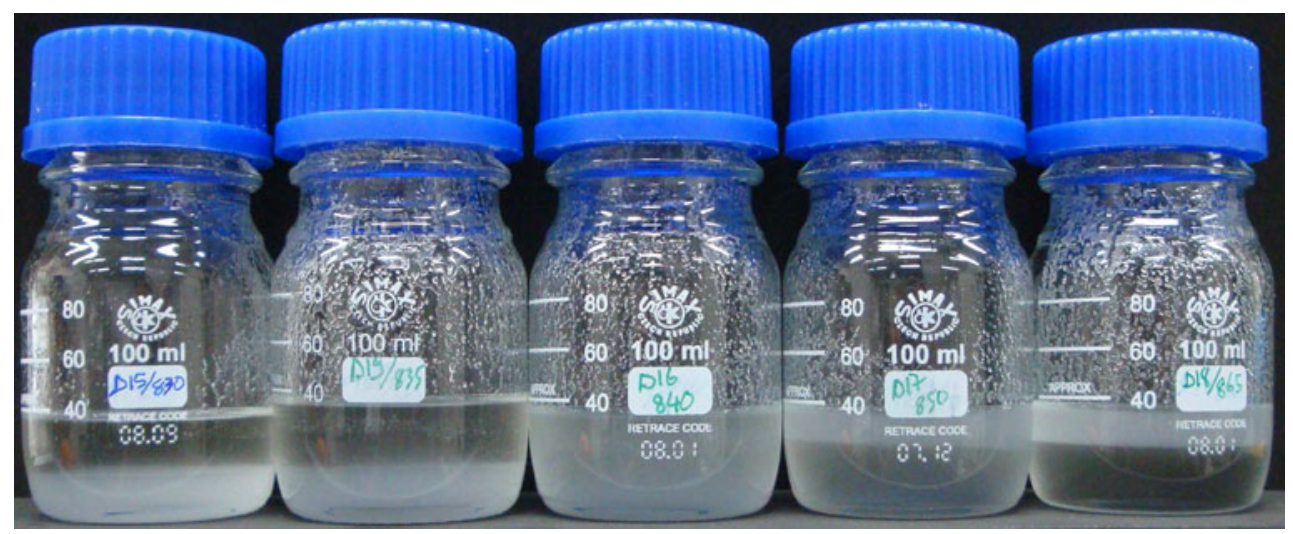

Fig. 7 The 1-week sedimentation experiment: from left to right, fluid densities of $1.1830 ; 1.1835 ; 1.1840 ; 1.1850$; and $1.1865 \mathrm{~g} / \mathrm{cm}^{3}$. The bright part results from a concentration of particles while the dark part means that the corresponding local volume is almost free of particles.

\section{Refractive index matching procedure}

\subsection{Selection of a RIM technique}

In Sect. 3, we presented different methods for matching the refractive index of a fluid mixture with that of particles. For the experimental application presented here, we used the improved temperature method based on the work of Koh (1991) and Koh et al. (1994); we refer the interested reader to the doctoral thesis of Wiederseiner (2010), in which the method was described at length and several improvements were brought. Here are the main reasons for this choice:

- The improved temperature method allowed us to prepare directly the suspension at the laser wavelength used in the FPIV and LIF measurements and not just to select the clearest suspension to the naked eye.

- It also allowed us to obtain a better index match and therefore to look farther into the concentrated suspension.

- The only parameter to control was temperature for an iso-index and iso-density suspension.

- We preferred this technique over the bulk sample techniques, because we had no guarantee that a bulk sample of PMMA made up of the material as the particles had the same refractive index. On the one hand, there are variations in the refractive index from one manufacture batch to another one and it was impossible to obtain both beads and a bulk piece of PMMA from the same batch. On the other hand, we preferred to use the particles directly because the bulk piece may change slightly during the production process of a bulk PMMA piece.

\subsection{Experimental protocol}

For the index matching experiments, we always started with binary density-matched fluids (Triton X100/DBH and
In the $1.1840-\mathrm{g} / \mathrm{cm}^{3}$ sample, no unmixing could be noted (in this experiment, particles and fluid were only density matched to allow better visualization of settlement)

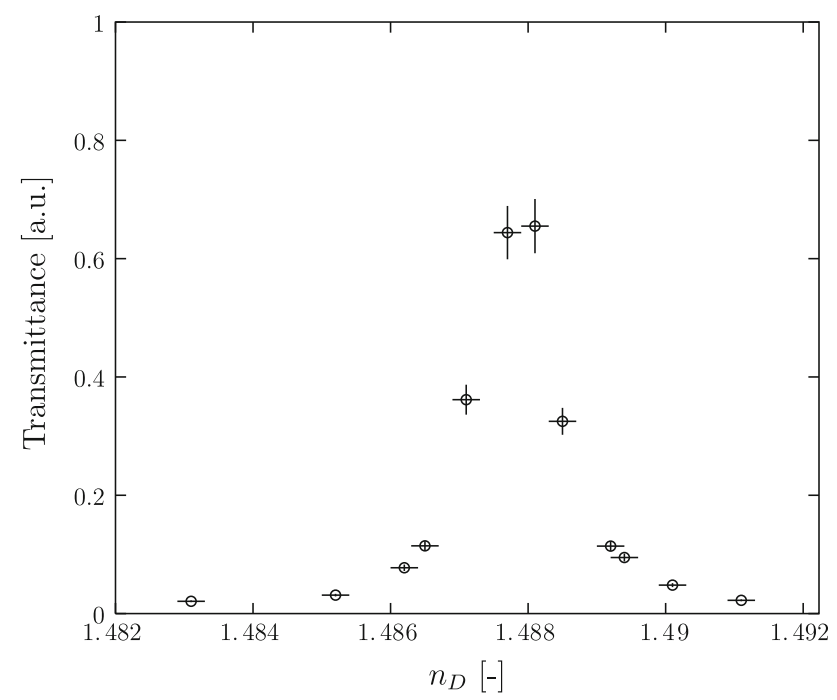

Fig. 8 The circles show the normalized light transmittance versus the index of refraction of the fluid at a controlled temperature and a given laser light wavelength. It shows the narrow interval in the peak of transmittance where the suspension is transparent. These results were obtained using the setup described in Sect. 3.3.4 and Fig. 4

UCON oil/DBH mixtures), which were prepared as explained in Sect. 5.3. This avoided sedimentation effects in the turbidity experiments

When using the temperature variation technique, we needed an initial guess for the PMMA refractive index of the particles. We took the refractive-index value at $20^{\circ} \mathrm{C}$ for PMMA from the literature (Cariou et al. 1986; see also Fig. 13). We prepared several fluid samples with different refractive indices around this value (from 1.4830 to 1.4910 in our case). We carried out preliminary turbidity experiments with this set of fluids. As shown in Fig. 8, there was a narrow peak in the transmittance curve. A four-digit precision is required in the measurement of the fluid refractive index if we want to take measurements in a 


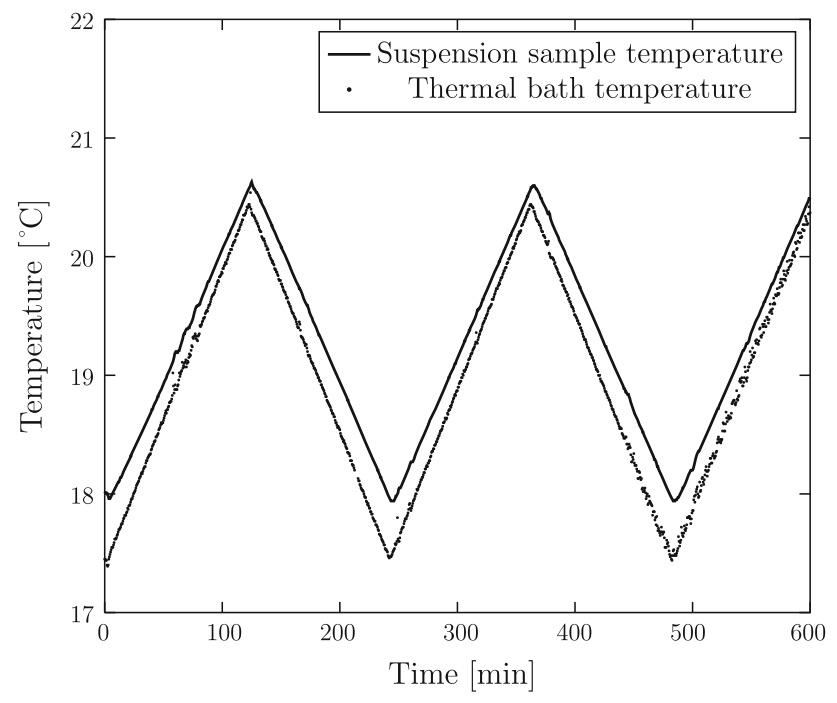

Fig. 9 Thermal control of a typical turbidity experiment involving five ramps, the offset between the two curves is due to the ambienttemperature difference. In this experiment, the solid concentration was $\phi_{\text {bulk }}=15 \%$, the mean particle diameter $d_{p}$ was $200 \mu \mathrm{m}$

concentrated suspension. Higher precision must be achieved if the objective is to enhance the field of visibility within the suspension.

When crudely adjusting the refractive index, we used the following variant of the Arago-Biot equation (5) based on the fact that we worked with density-matched components:

$\left(m_{1}+m_{2}\right) n_{12}=m_{1} n_{1}+m_{2} n_{2}$,

with $m_{i}(i=1,2)$ the component mass in the mixture of either pure fluid.

Although we primarily chose this equation for convenience, it turned out to be quite accurate. For fine tuning, we proceeded by trial and error by (i) adding a small amount of one of the binary fluids to increase or decrease the mixture refractive index and (ii) measuring the refractive index of the ternary mixture after sufficient mixing with an Atago RX-5000 $\alpha$ refractometer (ATAGO CO., LTD).

Once a suspension was prepared, a turbidity experiment was performed (see Fig. 4). We used a continuous wave Hulk Series 200-mW laser (ChangChun Dragon Lasers Co., Ltd). A 532-nm laser beam was sent through a 50/50 beam splitter (CVI Melles Griot - France, Part number BSNP-532-50-1025). The sample was temperature-controlled by two water cooled plates connected to a thermal bath (Julabo F34-HE circulator). Furthermore, a Pt100 temperature probe was directly immersed into the sample to record the sample temperature accurately during the experiments. A typical turbidity experiment temperature profile involving five ramps is shown in Fig. 9. The offset between the sample temperature (Fig. 9, red continuous line) and the thermal bath (Fig. 9, blue dotted curve) is due

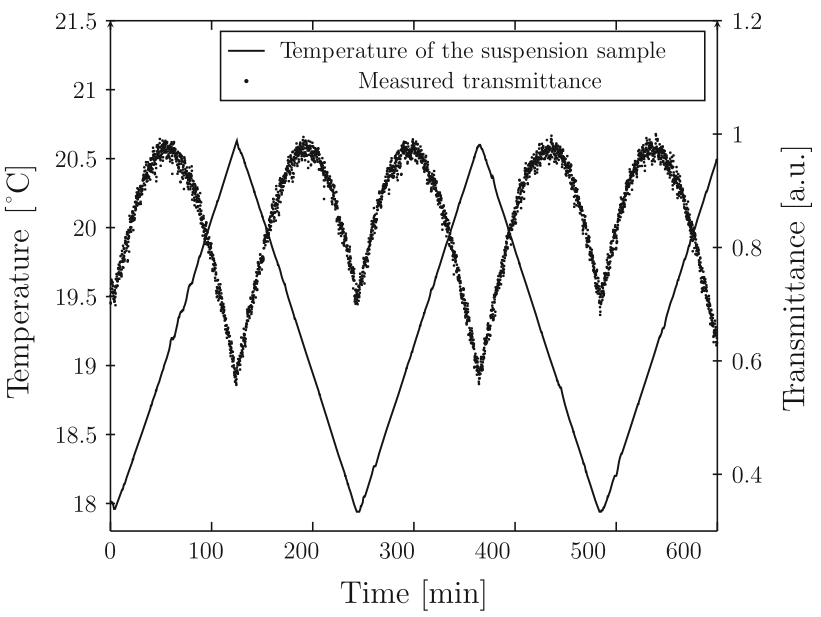

Fig. 10 Turbidity experiment of a PMMA particle suspension (mean concentration $\phi_{\text {mean }}$ of $15 \%$, mean particle diameter $d_{p \text {,mean }}=$ $100 \mu \mathrm{m}$ and laser light wavelength $\lambda=532 \mathrm{~nm}$ ). The dotes show the evolution with time of the measured light transmittance and the line show the suspension sample temperature. A maximum of transmittance can be found at $19.1^{\circ} \mathrm{C}$ for all the five temperature ramps as can be seen on Fig. 11

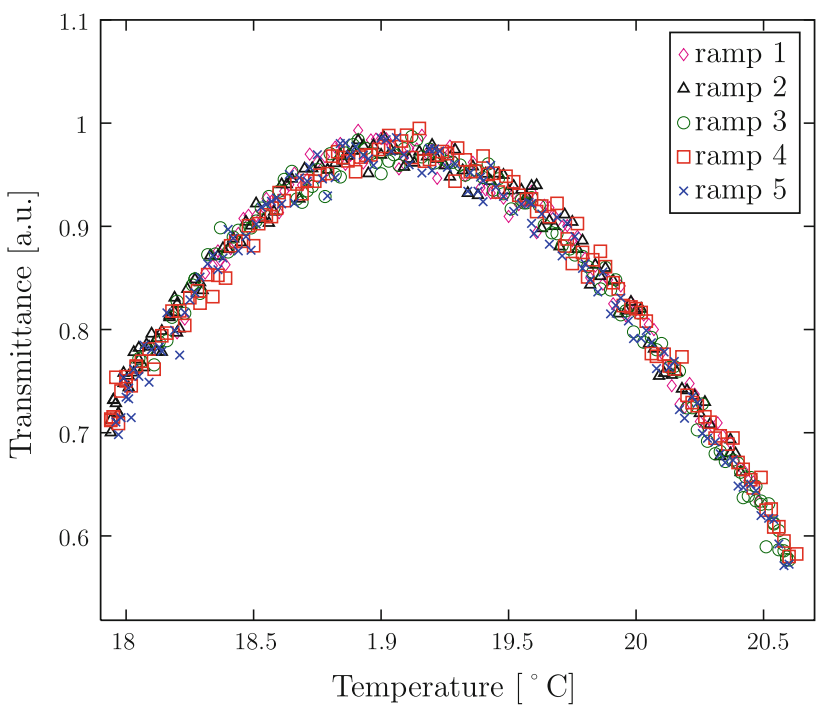

Fig. 11 Master curve from the five turbidity ramp experiments of Figs. 9 and 10

to the ambient temperature. The transmittance curve corresponding to the temperature profiles of Fig. 9 is shown on Fig. 10.

As shown by Fig. 11, the temperature gradient $\mathrm{d} T / \mathrm{d} t$ of $\pm 1.25^{\circ} \mathrm{C} / \mathrm{h}$ was small enough so as to avoid any skewness in the transmission curves due to thermal inertia. If not, the differences from the up and down ramps would have been more significant. From the master curve in Fig. 11, one can now deduce the temperature at which the ternary-fluid refractive index matches that of the particles. We still have to measure the refractive index of the fluid at the maximum 


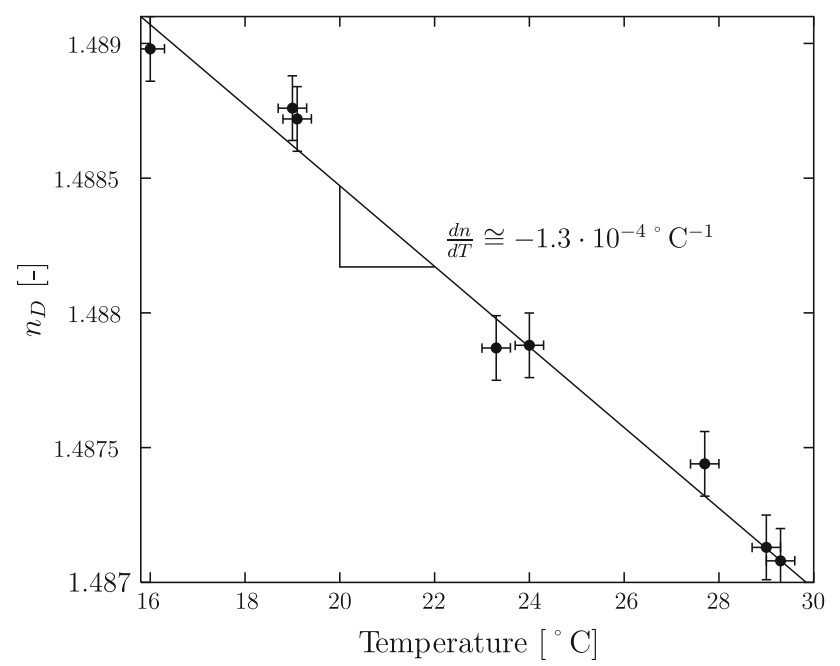

Fig. 12 Refractive index of the PMMA particles deduced from several turbidity experiments

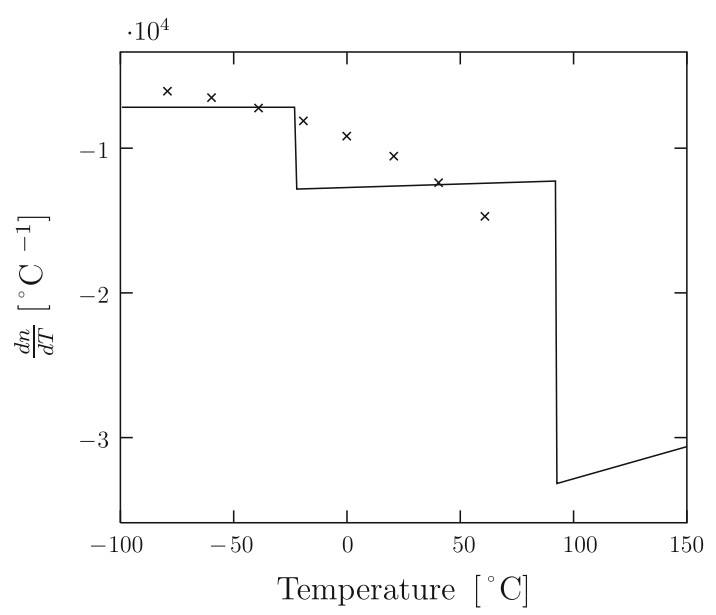

Fig. 13 Refractive index variation with temperature of solid PMMA (after Cariou et al. 1986); the solid line is the experimental result of Cariou et al. (1986) and the crosses represent the experimental results obtained by Waxler et al. (1979)

transmittance temperature using a refractometer. For Fig. 11, the maximum was at $19.10^{\circ} \mathrm{C}$. In Fig. 12, several turbidity experiments were conducted with different ternary fluid proportions and matching the PMMA particles at different temperatures. As shown in Fig. 12 the refractive index of our PMMA particles was finally obtained from a linear interpolation of the turbidity experiments and was estimated at 1.48847 (at a temperature of $20^{\circ} \mathrm{C}$ ). The variation in the refractive index with temperature was of approximately $-1.3 \times 10^{-4 \circ} \mathrm{C}^{-1}$. This value is in good agreement with measurements drawn from the literature (Cariou et al. 1986) with bulk PMMA, as shown by Fig. 13.

Conaghan and Rosen (1972) developed a theory that quantifies the degree of light scattering in a suspension as a function of the refractive indices of the two phases. The theory holds only in the limit of small volume fractions because only single scattering is considered.

The light transmittance through a sample of thickness $x$ is defined as:

$T \equiv \frac{I}{I_{0}}=\mathrm{e}^{-\tau x}$,

where $I$ and $I_{0}$ denote the suspension transmitted light intensity and clear fluid transmitted light intensity, respectively. For a perfectly matched system, we have $T=1$; otherwise, we have $T<1$. The turbidity $\tau$ is given by:

$\tau=\frac{3 \phi K}{2 d_{p}}$,

where $\phi$ denotes the particle concentration, $K$ the scattering coefficient, and $d_{p}$ the particle diameter. Normally, it is necessary to solve Maxwell's equation to obtain $K$. However for large particles $\left(d_{p} \gg \lambda\right)$, Van De Hulst (1957) derived the following relation:

$K=2-\frac{4}{\rho} \sin \rho+\frac{4}{\rho^{2}}(1-\cos \rho)$,

where

$\rho=\frac{2 \pi d_{p} n_{s}}{\lambda}\left|\frac{n_{f}}{n_{s}}-1\right|$.

In the equation above, $n_{f}$ and $n_{s}$ are the fluid and solid refractive indices.

Figure 14 compares Conaghan's equation with the experimental data used in Figs. 9, 10, and 11. Two concentrations are reported: $\phi=\phi_{\text {bulk }}=15$ and $4 \%$. The discrepancy between our experimental data and Conaghan's theoretical trend is likely to come from a partially satisfied hypotheses in the experiment. One of Conahan's assumptions is that the particles are of equal size. Even though our particles were in a narrow particle-size range (unsieved 50-300 $\mu \mathrm{m}$ range), they were not of equal size. Another possible cause is a statistical dispersion of the particles' refractive indices. To find the origins of this discrepancy, we should have conducted simulations and further experiments with well-sorted suspensions at lower concentrations and with several batch of particles. As a corollary, the simulation might provide the possibility of estimating the dispersion from the experimental results. The dispersion would indeed be mostly interesting as a purity criterion of a given batch. Another explanation may lie in the fact that by stirring the suspension in the laser beam path, we reduced the particle concentration in the highly sheared laser beam area. A 4\% suspension in Conaghan's equation seems to match our experimental results quite well, but we were unable to quantify shear- 


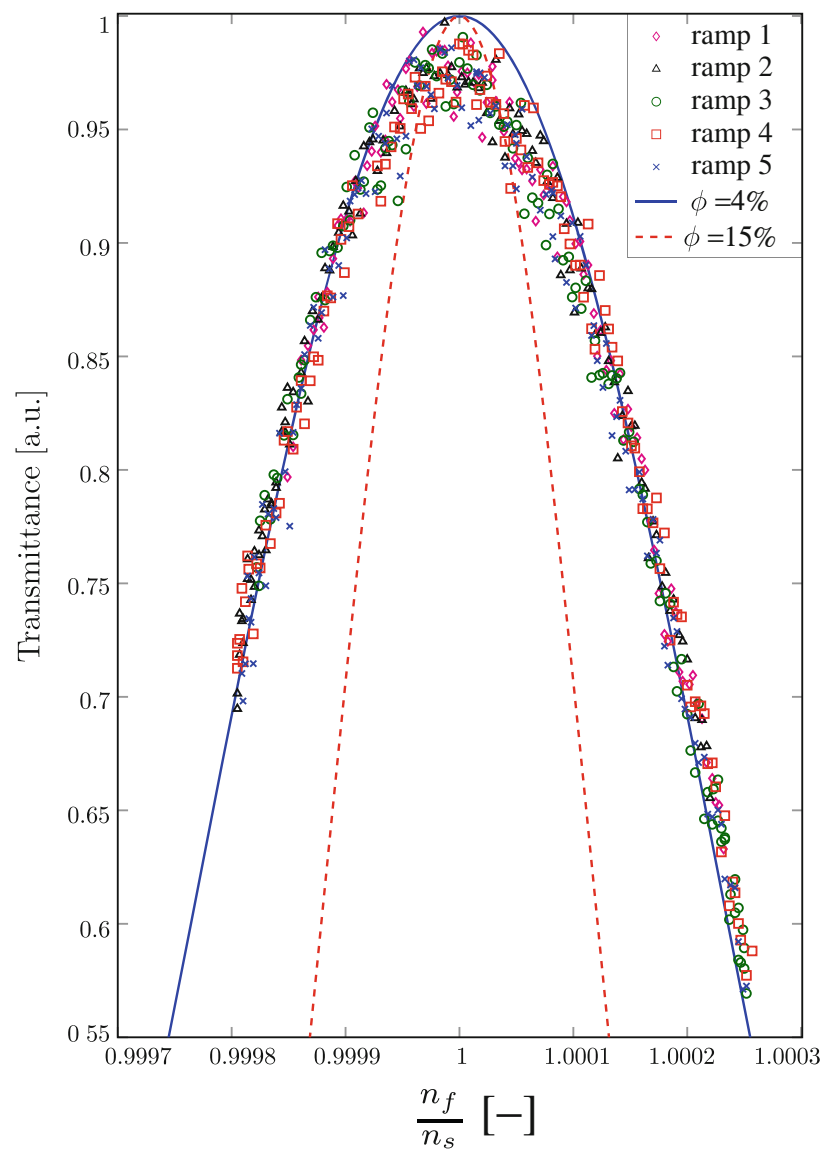

Fig. 14 Transmission vs. refractive index ratio $\frac{n_{f}}{n_{s}}$ of the typical experiment of Figs. 9, 10, and 11, marks are experimental: $\phi_{\text {bulk }}=$ $15 \%, d_{p \text {,mean }}=200 \mu \mathrm{m}, \lambda=532 \mathrm{~nm}$, and comparison with the theoretical transmittance curve $\left(n_{s}=1.48872\right)$ with a concentration $\phi_{\text {bulk }}$ of 15 and $4 \%$

induced segregation in our cell. A quantitative comparison is therefore not possible.

\subsection{Effect of the environment}

When matching the fluid refractive index, there are a few impediments to high precision matching (i.e., up to the fifth digit). For instance, during the experiments we conducted with three fluids, we could observe non-negligible variations in the refractive index with time. On the basis of a reproducible experiment described below, we concluded that this resulted from interactions between the three fluids (essentially Triton X100) and the laboratory environment. In this experiment, we loaded the refractometer with a small fluid sample and we performed a refractive index measurement every $15 \mathrm{~s}$. Because of the sample container geometry in the refractometer, the ratio between the airexposed surface to sample volume was very high. During a 24-h experiment, the sample was covered for some time with a polyethylene film to avoid air contact. During this

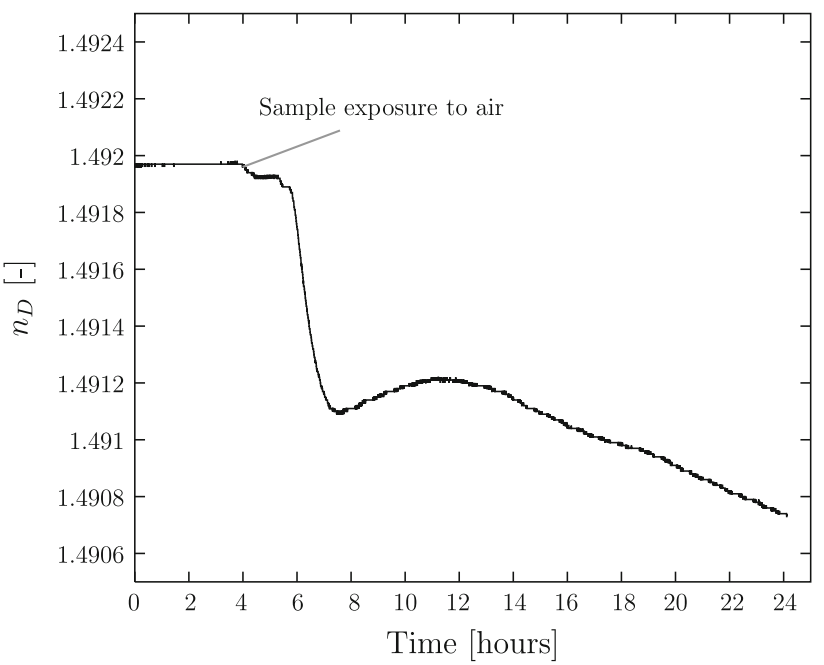

Fig. 15 Surrounding air effect on the refractive index of Triton X100: during $4 \mathrm{~h}$, the sample remained sealed and then the seal was opened to ambient air

time span, the fluid refractive index remained stable to within the measurement errors of the refractometer. Once the film was removed (after $4 \mathrm{~h}$ in the experiment of Fig. 15), the fluid refractive index started to decrease rapidly. This evolution was irreversible. We failed to find clear-cut reasons for this trend. We suspected that water could be the agent that modified the refractive index values as a result of vapor exchange with the ambient air, but we were unable to provide clear evidence.

Another experiment provided further evidence that water played a significant role in the decrease in the fluid refractive index. We put a ternary fluid mixture in a vacuum chamber (residual air pressure of $10 \mathrm{mbar}$ ) and simultaneously steered it to degas any residual dissolved water. After several days, we could measure a weight decrease of about $1.5 \%$ in the fluid mass and a substantial increase in the refractive index. Using the Arago-Biot equations (5) and (9) with $n_{12}$ the initial trimix refractive index, $n_{1}$ being the finally measured refractive index of the mixture, $m_{1}$ the final trimix weight, and $m_{2}$ the weight loss during the vacuum experiment, we found that the $n_{2}$ value was 1.33299 at $20^{\circ} \mathrm{C}$, i.e., the same as the refractive index of water.

The influence of water content on the refractive index was sufficiently important to disturb imaging into the suspension. The water decreased the refractive index by a value of $2 \times 10^{-4}$. This corresponds to an addition of $0.8 \%$ of water. Nevertheless, this water addition remained undetectable and within the measurement errors of the bulk rheological measurement, even for the measurement of the fluid alone.

The influence of water on the refractive index was less significant in the suspension used in the Couette and dambreak experiments (see Sect. 8): for all experiments, we used a reservoir which was as narrow as possible and ratio 
of the surface of the suspension exposed to air to the suspension volume was kept as low as possible. This water effect posed no problem when making velocity-profile measurements within the Couette cell. The main constraint was that we had to take the water content into account during the density matching procedure (see Sect. 5.3) and the refractive index matching procedure (see Sect. 6); another constraint was that the binary and ternary fluids had to be put under vacuum several times during the fluid preparation to avoid any effect of water on the final fluid density and refractive index. However, in the process of the rheologic experiments, the flowing part of the suspension showed a slow decrease in the refractive index with time. Velocity profiles could be taken for approximately $24 \mathrm{~h}$ until the refractive index mismatch became sufficiently noticeable to decrease the depth at which images could be taken.

\section{Flow motion measurement}

As discussed in Sect. 4, specific techniques have to be used for flow seeding in RIM fluids. In these experiments, we used fluorescent particles (see Sect. 4.2). The fluorescent dye used was rhodamine $6 \mathrm{G}$. Absorption peak occurred at $524 \mathrm{~nm}$ and the emission peak at $565 \mathrm{~nm}$. The onset of fluorescence was below $25 \mathrm{ps}$ and the light emission duration (99\% decay) is of $4.8 \mathrm{~ns}$ (Lam and Damzen 2003). It was therefore suitable to our PIV measurements. Rhodamine 6G was chosen because the laser wavelength $(532 \mathrm{~nm})$ was close to the maximum absorption of the dye and its high quantum yield. Furthermore, owing to the quantum efficiency of the CCD captor of the camera, which decreases from $55 \%$ at $500 \mathrm{~nm}$ to $39 \%$ at $600 \mathrm{~nm}$, rhodamine $6 \mathrm{G}$ was a better candidate compared to other dyes (such as pyromethene 597) (Fig. 16).

As explained in Sect. 4.2, how much fluorescent dye must be added results from a compromise between two effects. On the one hand, more dye increases the emitted light signal and, on the other hand, it moves the refractive index of the dyed particles away from the refractive index of the suspension, diminishing the suspension transparency. As shown by the experiments ran by Oki et al. (2002), adding a fluorescent dye to PMMA increases the PMMA refractive index with the dye concentration. As we can see in Fig. $17, n_{D}$ varies linearly with the rhodamine$6 \mathrm{G}$ concentration $C$, with slope $\Delta n_{D} / \Delta C$ of $1.8750 \mathrm{M}^{-1}$.

Assuming that the difference in the composition between the PMMA of Oki's measurements and ours has no effect on $\Delta n_{D} / \Delta C$ and that rhodamine-6G concentration in our particles after tagging is the same as the dye-solvent mixture concentration (leading to a dye concentration of $6 \times 10^{-4} \mathrm{M}$ in the PMMA particle) leads us to find

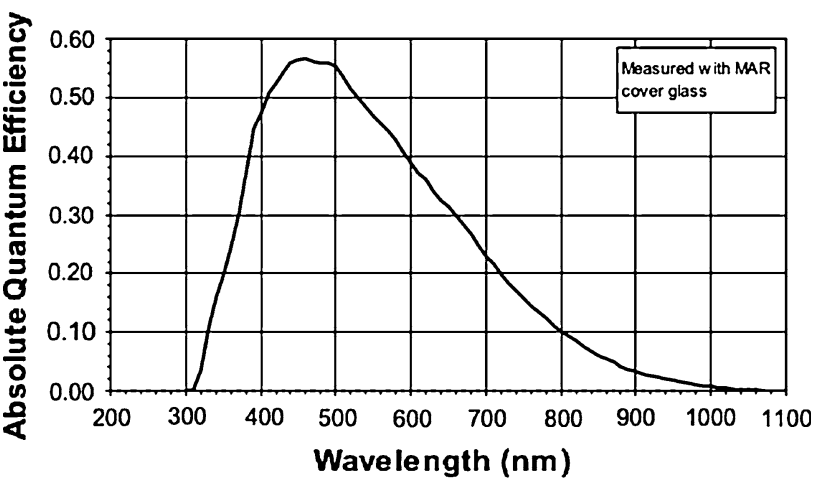

Fig. 16 Quantum efficiency of the Powerview Plus 2 Mpixel camera (after Kodak 2005)

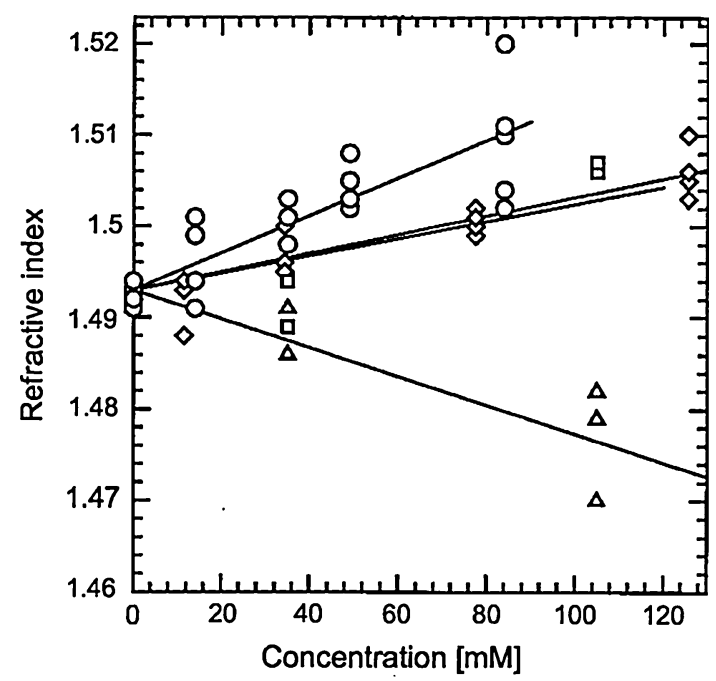

Fig. 17 Refractive index of dye-doped PMMA as fonction of a concentration of dopant: circles rhodamine 6G; diamonds 4-dicyanomethylene-2-methyl-6-p-dimethylaminostyryl-4H-pyran DCM; triangles Coumarin 500 (after Oki et al. 2002)

variations in the tagged-particle refractive index in the order of $1.1 \times 10^{-3}$. Although this value could not be checked experimentally, it seems reasonable. A small part of the particles being tagged, the effect of the refractiveindex mismatch for this small amount of particles seems to have almost no visible effect on suspension turbidity.

To determine the most suitable rhodamine-6G concentration for the tagged particles, we performed experiments using several concentrations. We ended up with a concentration of $6 \times 10^{-4} \mathrm{~mol} / \mathrm{l}$ of rhodamine $6 \mathrm{G}$ in the solvent during preparation. The tagged-particle synthesis was based on the following procedure (Lenoble 2005):

- first a $6 \times 10^{-4} \mathrm{~mol} / \mathrm{l}$ rhodamine solution $(\sim 200 \mathrm{ml})$ in ethanol is prepared;

- this solution is heated up to $35^{\circ} \mathrm{C}$; 
- three to four grams of particles are added to the solution;

- the whole is kept under continuous steering for $15 \mathrm{~min}$;

- particles are then placed on a sieve (Retsch sieves $200 \times 25 \mathrm{~mm}$, mesh of $180 \mu \mathrm{m}$ );

- they are rinsed thoroughly with clean ethanol; and

- finally the tagged beads are dried for a couple of hours in an air oven at $60^{\circ} \mathrm{C}$.

As mentioned in Sect. 4.2, the dye stability on the tagged particles is important. In the present case, the dye slowly went out of the particles, reducing image contrast with time. As long as the fluorescence signal of tagged particles is much stronger as the one of the fluid, this is not a problem for velocity measurements. However, in the case of particle concentration measurements, this effect becomes unacceptable. Nevertheless, to have the best possible images, we always used fresh suspensions in the velocity measurements experiments.

\section{Experimental results}

Typical images of RIM flow are shown in Fig. 18 for two different experimental setups: (i) the Couette experiment, in which a suspension filling the gap between two rotating cylinders is sheared at constant rate and (ii) the dam-break experiment, which consists in releasing a fixed volume of suspension down a flume.

We ran experiments in a wide-gap Couette cell, whose outer-cylinder diameter was $60 \mathrm{~mm}$ while the inner-cylinder diameter was $25 \mathrm{~mm}$. For some runs, we replaced the inner cylinder with a 6-blade vane, whose diameter was $25 \mathrm{~mm}$. The material was the same as the one described in Sect. 5. The cell was manufactured in quartz, which makes it possible to film inside it from the bottom. Maximum measurement depth was $35 \mathrm{~mm}$ in a suspension with volume fraction of 0.55 , i.e. through 350 fluid-particle interfaces. Figure 19a shows streamlines between the blades of the vane. The closed paths provided evidence of significant recirculation in the interblade space. Originally, vane geometries were used to measure the apparent yield stresses of dispersions (Russel 1936), but they have been recently used to measure other rheologic parameters. Indeed, a clear advantage over a smooth or roughened inner cylinder is that shear takes place inside the material and not at a solid boundary (solid boundaries locally disturb the flow of suspensions as a result of processes such as particle depletion and slipping). A recent review of the vane geometry can be found in an article of Barnes and Nguyen (2001). These authors warned the reader about the relevance of this tool when applied to highviscosity liquids. In particular, since the vane is assumed
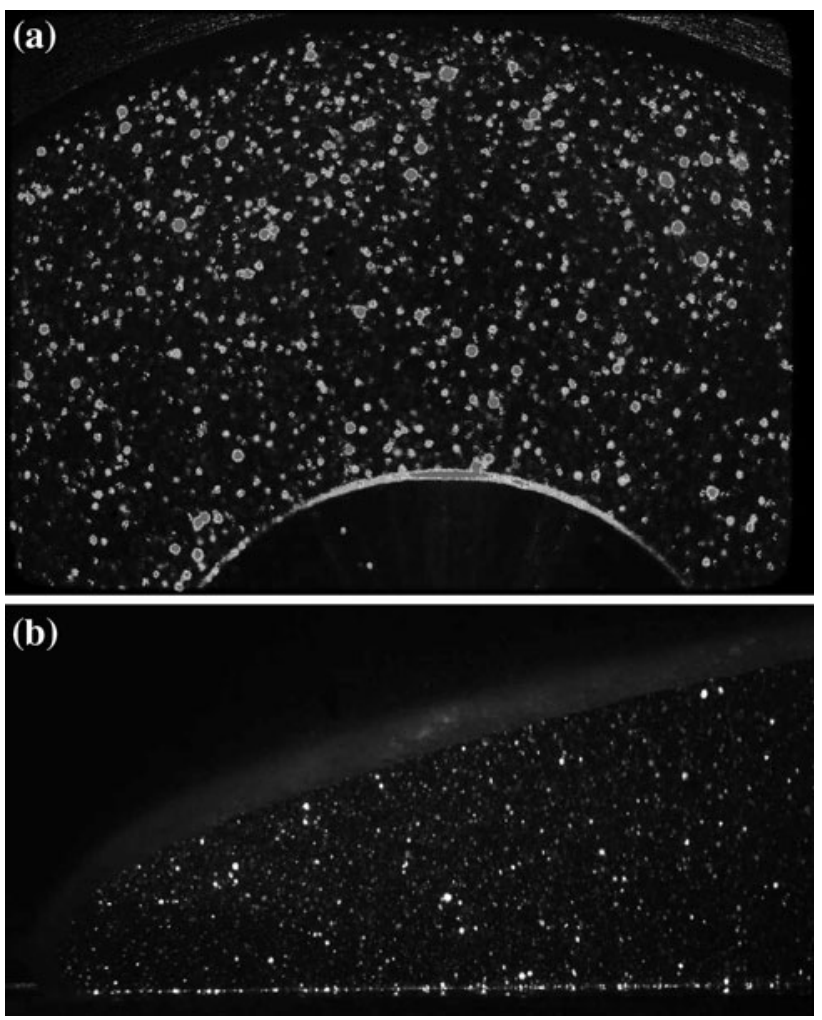

Fig. 18 a Typical PIV image in the Couette cell with a 0.55 volume fraction coarse particle suspension at $20 \mathrm{~mm}$ into the suspension. b Flow front (dam-break experiment) of a concentrated and refractive-index-matched suspension with a particle volume fraction of 0.58 and an inclination of $0^{\circ}$, images have been taken from the side at a depth of $20 \mathrm{~mm}$ into the fluid. The suspension flows from right to left and the bright dots are marked particles advected by the fluid, which are used as tracers to infer fluid velocity

to replace a rotating solid body, the material trapped within the blades should stay stationary (in the frame related to the blades) and rotates as a solid block. If the interblade space does not behave as a rigid body, i.e., if vortices and secondary flows occur, the boundary conditions are changed at the periphery of the blades, which makes it difficult any viscometric treatment of the data. The suspension behavior within the blades have been studied numerically (Savarmand et al. 2007; Potanin 2010), but there has been no experimental investigation to date. As far as we know, our experiments are the first report of flow recirculation within vane blades in a Couette cell. As shown by Fig. 19a, the velocity field exhibits flow recirculation patterns in the interblade space, confirming Barnes' hypothesis. The spacial resolution allows us to clearly identify the main vortex just behind each blade. There seems to be a secondary vortex rotating in the opposite direction in front of the blade, next to the central shaft. This recirculation process had a great influence on the apparent inner cylinder wall slip. In fact, we were unable to obtain a no-slip condition with the vane 
(a)
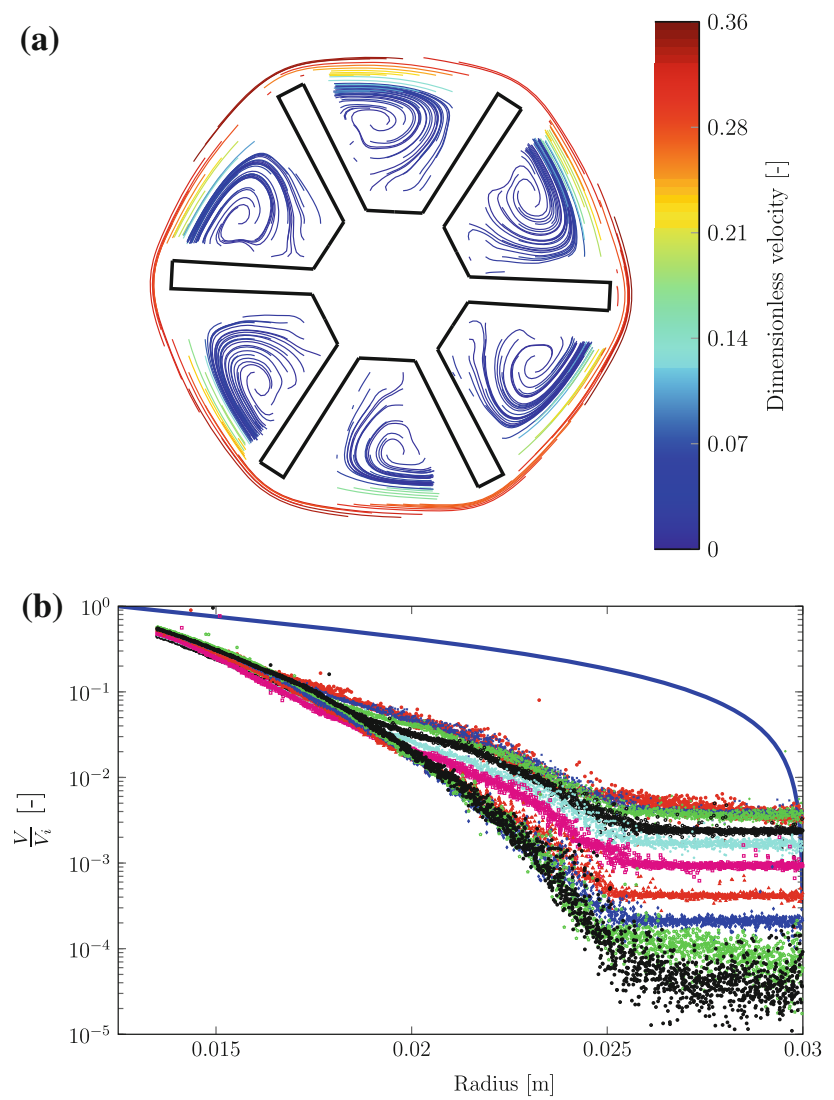

Fig. 19 a Streamlines of the interblade flow recirculations using a vane geometry: the inner 6-bladed vane has a diameter of $25 \mathrm{~mm}$ and an angular velocity of $1 \mathrm{rad} / \mathrm{s}$, the particle suspension has a volume fraction of 0.5 . The color scale represents the dimensionless velocity magnitude in the frame of reference attached to the vane (adimensionalized with the apparent outer cylinder velocity. The outer cylinder rotates clockwise in this frame of reference), $\mathbf{b}$ dimensionless azimuthal velocity profile at several inner cylinder velocities $V_{i}$ : $0.01 \mathrm{rad} / \mathrm{s}$ (red dots), $0.01802 \mathrm{rad} / \mathrm{s}$ (blue dots), $0.03246 \mathrm{rad} / \mathrm{s}$ (green dots), $0.05848 \mathrm{rad} / \mathrm{s}$ (black dots), $0.1054 \mathrm{rad} / \mathrm{s}$ (cyan dots), $0.1898 \mathrm{rad} / \mathrm{s}$ (majenta dots), $0.342 \mathrm{rad} / \mathrm{s}$ (red times symbol), $0.6162 \mathrm{rad} / \mathrm{s}$ (blue times symbol), $1.11 \mathrm{rad} / \mathrm{s}$ (green times symbol), and $2 \mathrm{rad} / \mathrm{s}$ (black times symbol). For comparison, the continuous blue line represents the newtonian velocity profile. The velocities are made dimensionless by dividing them by the inner cylinder velocity (inner sand-blasted cylinder $\varnothing=25 \mathrm{~mm}$, particle volume fraction $\phi=0.55$ )

geometry, although it is commonly used to fulfill this condition. The apparent velocity was lower at the periphery of the vane than at the surface of a sand-blasted inner cylinder, i.e. there was more slip with the vane. This observation questions the use of a vane geometry for concentrated particle suspensions. Figure $19 \mathrm{~b}$ shows the velocity profile across the gap for a roughened inner cylinder. Its angular velocity ranged from 0.01 to $10 \mathrm{rad} / \mathrm{s}$. The particle volume fraction was $\phi=0.55$. Maximum measurement depth was $35 \mathrm{~mm}$. In the steady-state regime (i.e. when shear induced particle diffusion was at

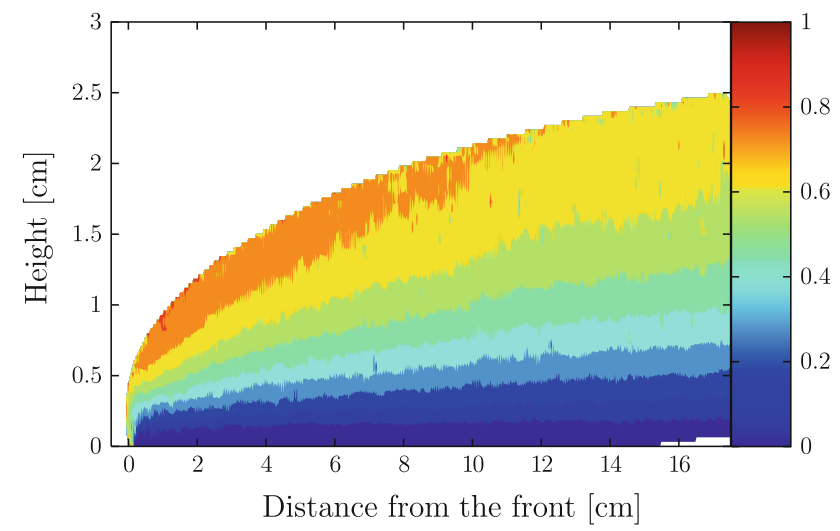

Fig. 20 Dimensionless velocity magnitude in the front of the flow in a dam-break experiment of a concentrated particle suspension $(\phi=0.58)$

equilibrium), the measured azimuthal-velocity profiles experienced a sup-exponential decay in the region close to the inner cylinder. These results are in agreement with MRI measurements (Ovarlez et al. 2006). However, near the outer cylinder, we measured an abrupt change in the profiles. Its origin is not yet clear, and we are unaware of earlier observations of this change. This kink in the profile implies that the shear rate $\dot{\gamma}$ remains always above a certain value. This result may corroborate the idea that there is of a critical shear rate $\dot{\gamma}_{c}$ below which no steady flow is possible, a scenario proposed by Coussot et al. (2009).

Dam break experiments (here, the sudden release of ten liters of concentrated suspension) were also carried out in a channel ( $3 \mathrm{~m}$ length and $10 \mathrm{~cm}$ in width). Figures $18 \mathrm{~b}$ and 20 show typical images of the channel experiments with the associated velocity field within the leading edge in concentrated suspension with a volume fraction $\phi=0.58$.

For both the Couette and the dam break experiments, velocity fields were computed using a modified version of the open source software called MatPIV (Sveen 2004). Computations were performed using a multiple-pass scheme with a sub-window size reduction from $128 \times 128$ to $64 \times 64$ and finally $32 \times 32$ pixels. Signal-to-noise ratio (SNR), global, local and velocity range filters were used to reject spurious correlation peaks and therefore wrong velocity vectors. As the velocity spans over a wide range, computation of the velocity profile cannot be achieved using a single set of images within a given length of time $\Delta t$. Indeed if the $\Delta t$ value was selected so that we are able to capture the velocity field close to the inner cylinder, the PIV algorithm could not properly compute the velocity field near the outer cylinder and vice versa. For this reason, the velocity profile was obtained using several sets of images with different $\Delta t$. 


\section{Conclusion}

RIM flow visualization has great potential to provide velocity profiles in a wide range of applications. It has been used for flow measurement within complex geometries, porous media, density-stratified flows and colloidal and non-colloidal concentrated particle suspensions. The versatility of the technique allows for a wide range of measurement in usually opaque media. As exemplified in this paper, different flow measurement techniques, such as PIV, PTV, LDV, or LIF can be used in combination with RIM fluids. At present time, these methods provide many advantages over NMR or RMI techniques. The limitations of RIM measurement stem from:

- the homogeneity of the optical properties of the particles essentially (and the fluid);

- the procedure and ability to match the refractive indiced properly;

- the temperature control;

- the light wavelength;

- the humidity control.

All these factors influence the depth down to which measurement can be performed. To date, most measurements were taken through 40-100 particle-fluid interfaces, but a careful control allowed us to obtain velocity profiles through approximately 350 interfaces.

Acknowledgments The work presented here was supported by the Swiss National Science Foundation under grant number 200021105193/1 and specific funds provided by EPFL (vice-présidence à la recherche). We also thank AXA for additional funding.

\section{Appendix 1: Techniques used in combination with RIM for the study of the dynamics of concentrated particle suspensions}

- PIV

- Abbas and Crowe (1987)

- Chen and Fan (1992)

- Hassan et al. (1992), Hassan and Dominguez-Ontiveros (2008)

- Lenoble et al. (2005a, b)

- Zachos et al. (1996)

- PTV

- Breedveld et al. (1998), 2001a, b, 2002)

- Chen et al. (2005)

- Ham and Homsy (1988)

- Karnis et al. (1966)

- Leighton and Acrivos (1987)

- Mikami et al. (1997, 2001)
- Mondy et al. (1986)

- Nicolai and Guazzelli (1995), Nicolai et al. (1995, 1996)

- Wang et al. (2008)

- LDV

- Averbakh et al. (1997), Shauly et al. (1997)

- Haam (1996), Haam and Brodkey (2000), Haam et al. (2000)

- Jana et al. (1995)

- Kapoor and Acrivos (1995)

- Koh et al. (1994)

- Kohnen and Bohnet (2001)

- Lyon and Leal (1998a, b)

- Park et al. (1989)

- Nouri et al. (1986, 1987, 1988), Yianneskis and Whitelaw (1983)

- Wildman et al. (1992)

- Zisselmar and Molerus (1979)

- LIF

- Chen et al. (2005)

- Lenoble et al. (2005a, b)

- Mikami et al. (2001)

- Other

- Ackerson and Pusey (1988)

- Burdett et al. (1981)

- Graham and Bird (1984), Graham and Steele (1984a, b)

- Timberlake and Morris (2002)

\section{Appendix 2: Refractive index matched fluid recipes}

In this section, the reader will find other recipes used in the literature to match the refractive index of particles.

- PMMA (Polymethylmethacrylate)

- Potassium thiocyanate solution: Gijsen et al. (1996)

- Triton X100 (Sigma Aldrich): Jana et al. (1995), Kapoor and Acrivos (1995)

- Glycerin $40.67 \%$ by weight, ethylene glycol $22.82 \%$ by weight and styrene glycol $36.51 \%$ by weight: Leighton and Acrivos (1987)

- Aqueous zinc iodide solution: Hendriks and Aviram (1982)

- Kerosine and an oil mixture (Shellflex 214 BG): Bovendeerd et al. (1987)

- Demineralized water, zinc chloride: Stöhr et al. (2003)

- Dow Corning fluid $55084 \%$ by weight and Dow Corning fluid $55616 \%$ by weight: Braun et al. 
(1991), Peurrung et al. (1995), Rashidi et al. (1996), Stöhr et al. (2003)

- Dow Corning fluid 550 and Dow Corning fluid 200: Johnston et al. (1975)

- Dow Corning fluid $55698 \%$ by weight and Dow Corning fluid $2002 \%$ by weight: Stöhr et al. (2003)

- Demineralized water, zinc chloride and Triton X100 (Sigma Aldrich): Breedveld et al. (1998, 2001a, b, 2002), Krishnan et al. (1996), Timberlake and Morris (2002)

- 1,1,2,2 tetrabromoethane (Eastman Kodak) $14.07 \%$ by weight, polyalkylen glycol (UCON oil $75 \mathrm{H}$ 90 '000) $35.66 \%$ by weight, Triton X100 (Sigma Aldrich) $50.27 \%$ by weight and Tinuvin 328 (Ciba Specialty Chemicals) $0.1 \%$ by weight: Abbott et al. (1993), Averbakh et al. (1997), Graham et al. (1991), Milliken et al. (1989), Shauly et al. (1997)

- Decahydronaphthalene, tetrahydronaphthalene and cyclohexylbromide: Chaudhuri et al. (2008), Gao and Kilfoil (2007)

- Decahydronaphthalene, tetrahydronaphthalene and carbon tetrachloride: Kegel and van Blaaderen (2000)

- Decahydronaphthalene, tetrahydronaphthalene: Ackerson and Pusey (1988)

- Cyclohexylbromide and decahydronaphthalene: Dibble et al. (2006), Wang et al. (2008), Weeks et al. (2000)

- Cyclohexylbromide, decahydronaphthalene and tetrabutyl- ammonium chloride: Kaufman and Weitz (2006)

- Polyalkylene glycol oil (UCON oil 50-HB-5100, Union Carbide) and 1,1,2,2 tetrabromoethane (Aldrich Chemical Company): Graham and Bird (1984)

- Di-butylphtalate: Yianneskis and Whitelaw (1983)

- para-cymene: Haam (1996), Haam et al. (2000), Hassan and Dominguez-Ontiveros (2008)

- Tetraline and $40 \%$ by weight turpentine: Horvay and Leuckel (1984), Kapoor and Acrivos (1995), Liu et al. (1989, 1990), Nouri et al. (1986, 1987, 1988); Thompson (1990)

- Polyglycol oil (UCON oil 50-HB-5100, Union Carbide) $33.7 \%$ by weight, terpineol $41.8 \%$ by weight, 1,1,2,2 tetrabromohethane (Aldrich Chemical Company) $24.4 \%$ by weight and Tinuvin (Ciba Geigy) $0.1 \%$ by weight: Mondy et al. (1986)

- L42 organosilicone fluid (Union Carbide Co.) 27\% by weight and 550 fluid (Dow chemical Co.) $73 \%$ by weight: Dybbs and Edwards (1984), Northrup et al. (1991a, b, 1993)

- Ethyl and benzyl alcohol: Hassan and DominguezOntiveros (2008)
- Aqueous sodium iodide solution and glycerin: Zerai et al. (2005)

- Aqueous sodium iodide solution (60\% concentration): Hassan and Dominguez-Ontiveros (2008), Okumura et al. (2005), Parker and Merati (1996), Uzol et al. (2002), Yuki et al. (2008)

- 1,6 dibromohexane (Aldrich caltalogue no. D4,1007), poly-alkylen glycol (UCON oil $75 \mathrm{H} \mathrm{450)} \mathrm{and}$ Triton X100 (Sigma Aldrich): Lyon and Leal (1998a, b), Wiederseiner (2010)

- Hexadecane and microscope oil (Sigma-Aldrich S150): Lenoble et al. (2005a, b)

- Aqueous solution of potassium thiocyanate and ammonium thiocyanate: Budwig et al. (1993a)

- Tetrachloroethylene: Kannemans (1979)

- PS (polystyrene)

- 1-methylnaphthalene (Aldrich catalogue number M5,680-8), 1-chloronaphthalene (Aldrich C5,7650 ), polyalkylene glycol (UCON oil 75-H-90'000, Dow Chemicals Co.): Koh (1991), Koh et al. (1994)

- 1-methylnaphthalene $28 \%$ by volume, 1 -chloronaphthalene $31 \%$ by volume and tetraline $41 \%$ by volume: Cui and Adrian (1997)

- PVA (Polyvinyl acetate)

- Polyglycol oil (UCON oil 50-HB-5100, Union Carbide) and $4 \%$ by volume tetrabromohethane: Karnis et al. (1966)

- Nylon

- Pale 4 oil (oxidized castor oil, Baker Castor oil Co.) and tetrabromoethane: Karnis et al. (1966)

- Glass

- Glycerine and water: Park et al. (1989)

- Soddard solvent and mineral oil: Park et al. (1989)

- Glycerol: Cenedese and Viotti (1996), Moroni and Cushman (2001)

- Esso Marcol 82 and Primol 352: Saleh et al. (1992, 1993)

- Dow Corning fluid 550 and Dow Corning fluid 556: Wang and Khalili (2002), Yarlagadda and Yoganathan (1989)

- Oil (Pharma 5, DEA) and a light protective liquid (Eusolex, Merck): Kohnen and Bohnet (2001)

- Tetrechloroethylene and Freon113: Varty (1984)

- Methylbenzoate at $25^{\circ} \mathrm{C}$ : Zisselmar and Molerus (1979)

- Light fuel oil and 30\% by volume of palatinol C: Durst et al. (1979)

- Xylen and $44 \%$ by volume and Varsol: Elphick et al. (1984) 
- Tetralin and silicone oil in proportion (1:2.57, by weight): Chen et al. (2005), Mikami et al. (1997, 2001)

- Alkyl benzyl phthalate plasticizer, named Santicizer 278 and produced by Monsanto: Ham and Homsy (1988), Nicolai and Guazzelli (1995), Nicolai et al. (1995, 1996)

- Isopropyl alcohol and methylnaphthalene: Hassan and Dominguez-Ontiveros (2008)

- Diethylphthalate: Hassan and Dominguez-Ontiveros (2008)

- Sodium Iodide water solution (55\% by weight): Chen and Fan (1992), Jacobs et al. (1988), Mehta et al. (2007), Tanaka (1999)

- Tetralin and clear coal oil: Zachos et al. (1996)

- Silica gel

- Chloroform and water: Abbas and Crowe (1987)

- Water solution of sodium iodide (50\%): Chen (1991), Chen and Fan (1992), Chen et al. (1992), Kadambi et al. (1990), Narrow et al. (2000), Wildman et al. (1992)

- Benzyl alcohol $45 \%$ by volume and ethyl alcohol $55 \%$ by volume: Cui and Adrian (1997)

- Fused quartz

- Tertaethylene glycol: Stephenson and Stewart (1986)

- Tetrahydropyran-2-methanol: Stephenson and Stewart (1986)

- Cyclooctane and cyclooctene: Stephenson and Stewart (1986)

- R.P. Cargille Laboratories fluid mixture: Montemagno and Gray (1995)

- Silicon rubber

- Methylcylohexane and water glycerin mixture: Burdett et al. (1981)

- water, glycerin and sodium chloride: Shuib et al. (2010)

- Other: Immiscible fluid-fluid mixtures

- Glycerol and potassium dihydrogen phosphate (monobasic): Alahyari and Longmire (1994)

- Ethanol and Epsom salt solutions: Atsavapranee and Gharib (1997)

- Sugar and Epsom salt as solutes in water: McDougall (1979)

- Ethyl alcohol and salt ( $\mathrm{NaCl})$ : Daviero et al. (2001), Hannoun et al. (1985, 1988)

- Fluoropolymer (FEP) was tested in water: Hassan and Dominguez-Ontiveros (2008)
- Sucrose-water continuous phase; trichlorotrifluoroethane-1- octanol droplet phase liquid-liquid system: Budwig (1994), Budwig et al. (1993b)

- n-heptane and 50\% water glycerol mixture: Augier et al. (2003)

- silicone oil and a water glycerol mixture: Ninomiya and Yasuda (2006)

\section{References}

Abbas MA, Crowe CT (1987) Experimental study of the flow properties of a homogenous slurry near transitional reynolds numbers. Int J Multiph Flow 13(3):357-364

Abbott J, Mondy L, Graham A, Brenner H (1993) Techniques for analysing the behaviour of concentrated suspensions. In: Roco M (eds) Particulate two-Phase flow. Butterworth-Heinemann, Boston, pp 3-32

Abott J, Tetlow N, Graham A, Altobelli S, Fukushima E, Mondy L, Stephens T (1991) Experimental observations of particle migration in concentrated suspensions: couette flow. J Rheol 35:113-795

Ackerson BJ, Pusey PN (1988) Shear-induced order in suspensions of hard spheres. Phys Rev Lett 61(8):1033

Alahyari A, Longmire EK (1994) Particle image velocimetry in a variable-density flow-application to a dynamically evolving microburst. Exp Fluids 17(6):434-440

Aminabhavi TM (1984) Use of mixing rules in the analysis of data for binary liquid mixtures. J Chem Eng Data 29(1):54-55

Ancey C (2005) Solving the couette inverse problem by using a wavelet-vaguelette decomposition. J Rheol 49:441-460

Ancey C (2007) Plasticity and geophysical flows: a review. J Nonnewton Fluid Mech 142:4-35

Ancey C, Coussot P (1999) Transition from frictional to viscous regime for granular suspensions. C R Acad Sci Paris 327:515-522

Arago D, Biot J (1806) Mém acad France 7

Atsavapranee P, Gharib M (1997) Structures in stratified plane mixing layers and the effects of cross-shear. J Fluid Mech 342(1):53-86

Augier F, Morchain J, Guiraud P, Masbernat O (2003) Volume fraction gradient-induced flow patterns in a two-liquid phase mixing layer. Chem Eng Sci 58(17):3985-3993

Averbakh A, Shauly A, Nir A, Semiat R (1997) Slow viscous flows of highly concentrated suspensions-part I: laser-doppler velocimetry in rectangular ducts. Int J Multiph Flow 23(3):409-424

Barnes H (1995) A review of the slip (wall depletion) of polymer solutions, emulsions and particle suspensions in viscosimeters: its cause, character, and cure. J Nonnewton Fluid Mech $56: 221-251$

Barnes H, Nguyen Q (2001) Rotating vane rheometry-a review. J Nonnewton Fluid Mech 98:1-14

Bonn D, Rodts S, Groenink M, Rafai S, Shahidzadeh-Bonn N, Coussot P (2008) Some applications of magnetic resonance imaging in fluid mechanics: complex flows and complex fluids. Annu Rev Fluid Mech 40:209-233

Bovendeerd PHM, Van Steenhoven AA, Van De Vosse FN, Vossers G (1987) Steady entry flow in a curved pipe. J Fluid Mech Digit Arch 177(1):233-246

Braun MJ, Canacci VA, Hendricks RC (1991) Flow visualization and quantitative velocity and pressure measurements in simulated single and double brush seals. Tribol Trans 34(1):70-80 
Breedveld V, Van Den Ende D, Tripathi A, Acrivos A (1998) The measurement of the shear-induced particle and fluid tracer diffusivities in concentrated suspensions by a novel method. J Fluid Mech 375(1):297-318

Breedveld V, Van Den Ende D, Bosscher M, Jongschaap RJJ, Mellema J (2001) Measuring shear-induced self-diffusion in a counterrotating geometry. Phys Rev E 63(2):021,403

Breedveld V, Van Den Ende D, Jongschaap R, Mellema J (2001) Shear-induced diffusion and rheology of noncolloidal suspensions: time scales and particle displacements. J Chem Phys 114(13):5923-5936

Breedveld V, Van Den Ende D, Bosscher M, Jongschaap RJJ, Mellema J (2002) Measurement of the full shear-induced selfdiffusion tensor of noncolloidal suspensions. J Chem Phys 116(23):10529-10535

Brown JM, Kadlubowski BM, Forney LJ, Sommerfeld JT (1996) Density gradient columns: dynamic modeling for linear profiles. Rev Sci Instr 67(11):3973-3980

Budwig R (1994) Refractive index matching methods for liquid flow investigations. Exp Fluids 17(5):350-355

Budwig R, Elger D, Hooper H, Slippy J (1993) Steady flow in abdominal aortic-aneurysm models. J Biomech Eng Trans ASME 115(4):418-423

Budwig R, Martinez J, Carlson T (1993b) Hydrodynamic and mass transfer characteristics of acoustically levitated and oscillated droplets. Bull Am Phys Soc 33

Burdett ID, Webb DR, Davies GA (1981) A new technique for studying dispersion flow, holdup and axial mixing in packed extraction columns. Chem Eng Sci 36(12):1915-1919

Callaghan PT (1999) Rheo-NMR: nuclear magnetic resonance and the rheology of complex fluids. Rep Progr Phys 62(4):599-670

Cariou JM, Dugas J, Martin L, Michel P (1986) Refractive-index variations with temperature of PMMA and polycarbonate. Appl Optics 25(3):334-336

Cenedese A, Viotti P (1996) Lagrangian analysis of nonreactive pollutant dispersion in porous media by means of the particle image velocimetry technique. Water Resour Res 32(8):2329-2343

Chaudhuri P, Gao Y, Berthier L, Kilfoil M, Kob W (2008) A random walk description of the heterogeneous glassy dynamics of attracting colloids. J Phys Condens Matter 20(24):244,1260953-8984

Chen RC (1991) Experimental and numerical studies of solid-liquid multiphase flow in pipes. PhD thesis, Case Western Reserve University

Chen RC, Fan LS (1992) Particle image velocimetry for characterizing the flow structure in three-dimensional gas-liquid-solid fluidized beds. Chem Eng Sci 47(13-14):3615-3622

Chen RC, Tzeng JW, Reese J, Fan LS (1992) Bed flow structure of a three-dimensional three-phase fluidized bed. In: AIChE Annual Meeting, Miami Beach

Chen B, Mikami F, Nishikawa N (2005) Experimental studies on transient features of natural convection in particles suspensions. Int J Heat Mass Transf 48(14):2933-2942

Christiansen C (1884) Untersuchungen nber die optischen Eigenschaften von fein verteilten Körpern. Ann Phys Chem 23:298-306

Christiansen C (1885) Untersuchungen nber die optischen Eigenschaften von fein verteilten Körpern. Ann Phys Chem 24:439446

Conaghan B, Rosen S (1972) The optical properties of two-phase polymer systems: single scattering in monodispese, non-absorbing systems. Polym Eng Sci 12(2):134-139

Coombs SH (1981) A density-gradient column for determining the specific gravity of fish eggs, with particular reference to eggs of the mackerel scomber scombrus. Mar Biol 63(1):101-106
Coussot P (2005) Rheometry of pastes, suspensions and granular materials. Wiley, New York

Coussot P, Raynaud J, Ancey C (2003) Combined MRI-rheometry determination of the behavior of mud suspensions. In: Chen C, Rickenmann D (eds) Debris flow mechanics and mitigation conference. Mills Press, Davos, pp 291-301

Coussot P, Tocquer L, Lanos C, Ovarlez G (2009) Macroscopic vs. local rheology of yield stress fluids. J Nonnewton Fluid Mech 158:85-90

Cui M, Adrian R (1997) Refractive index matching and marking methods for highly concentrated solid-liquid flows. Exp Fluids 22:261-264

Dale D, Gladstone F (1858) Phil Trans 148:887

Dale D, Gladstone F (1864) Phil Trans 153:317

Daviero GJ, Roberts PJW, Maile K (2001) Refractive index matching in large-scale stratified experiments. Exp Fluids 31(2):119-126

Davis RH, Acrivos A (1985) Sedimentation of noncolloidal particles at low reynolds numbers. Annu Rev Fluid Mech 17(1):91

Dibble CJ, Kogan M, Solomon MJ (2006) Structure and dynamics of colloidal depletion gels: coincidence of transitions and heterogeneity. Phys Rev E 74(4):041403

Durst F, Keck T, Kleine R (1979) Turbulence quantities and reynolds stress in pipe flow of polymer solutions measured by twochannel laser-doppler anemometry. In: Proceedings of 6th symposium on Turbulence, Rolla

Durst F, Mnller R, Jovanovic J (1988) Determination of the measuring position in laser-doppler anemometry. Exp Fluids 6(2):105-110

Dybbs A, Edwards RV (1984) An index-matched flow system for measurements of flow in complex geometries. In: Proceedings of 2nd international symposium on application of LDA to fluid mechanics, Lisbon, pp 171-184

Einstein A (1906) Eine neue Bestimmung der Moleknldimensionen. Ann Phys 19:289

Einstein A (1911) Berichigung zu meiner Arbeit: "Eine neue Bestimmung der Moleknldimensionen”. Ann Phys 34(339):591-592

Elkins CJ, Alley MT (2007) Magnetic resonance velocimetry: applications of magnetic resonance imaging in the measurement of fluid motion. Exp Fluids 43:823-858

Elphick RV, Martin WW, Currie IG (1984) Application of lda to high reynolds number cross flow. In: Proceedings of 2 nd international symposium on application of LDA to fluid mechanics, Lisbon

Fukushima E (1999) Nuclear magnetic resonance as a tool fo study flow. Annu Rev Fluid Mech 31(1):95-123

Gao Y, Kilfoil ML (2007) Direct imaging of dynamical heterogeneities near the colloid-gel transition. Phys Rev Lett 99(7):078301

Gijsen FJH, Palmen DEM, van der Beek MHE, van de Vosse FN, van Dongen MEH, Janssen JD (1996) Analysis of the axial flow field in stenosed carotid artery bifurcation models-LDA experiments. J Biomech 29(11):1483-1489

Graham A, Bird R (1984) Particle clusters in concentrated suspensions. 1. experimental observations of particle clusters. Ind Eng Chem Fundam 23:406-410

Graham A, Steele R (1984) Particle clusters in concentrated suspensions. 2. information theory and particle clusters. Ind Eng Chem Fundam 23:411-420

Graham A, Steele R (1984) Particle clusters in concentrated suspensions. 3. prediction of suspension viscosity. Ind Eng Chem Fundam 23:420-425

Graham A, Altobelli S, Fukushima E, Mondy L, Stephens T (1991) Note: NMR imaging of shear induced diffusion and structure in concentrated suspensions udergoing couette flow. J Rheol 35(1):191-201

Guyon E, Hulin JP, Petit L (2001) Hydrodynamique physique. EDP Sci 
Haam SJ (1996) Multiphase research on solid-liquid dispersion. PhD thesis, The Ohio State University

Haam SJ, Brodkey RS (2000) Motions of dispersed beads obtained by particle tracking velocimetry measurements: part II. Int J Multiph Flow 26(9):1419-1438

Haam SJ, Brodkey RS, Fort I, Klaboch L, Placnik M, Vanecek V (2000) Laser doppler anemometry measurements in an index of refraction matched column in the presence of dispersed beads: part I. Int J Multiph Flow 26(9):1401-1418

Ham JM, Homsy GM (1988) Hindered settling and hydrodynamic dispersion in quiescent sedimenting suspensions. Int $\mathrm{J}$ Multiph Flow 14(5):533-546

Handley D (1957) Studies of the motion of particles in liquid fluidised beds. PhD thesis, University of Leeds

Hannoun IA, Fernando HIS, List El (1985) Matching the refractive index in density stratified flows. Technical report, California Institute of Technology

Hannoun IA, Fernando HJS, List EJ (1988) Turbulence structure near a sharp density interface. J Fluid Mech Digit Arch 189(1):189-209

Hassan YA, Dominguez-Ontiveros EE (2008) Flow visualization in a pebble bed reactor experiment using PIV and refractive index matching techniques. Nucl Eng Des 238(11):3080-3085

Hassan YA, Blanchat TK, Seeley CH Jr, Canaan RE (1992) Simultaneous velocity measurements of both components of a two-phase flow using particle image velocimetry. Int J Multiph Flow 18(3):371-395

Heller W (1945) The determination of refractive indices of colloidal particles by means of a new mixture rule or from measurements of light scattering. Phys Rev 68(1-2):5-10

Heller W (1965) Remarks on refractive index mixture rules. J Phys Chem 69(4):1123-1129

Hendriks F, Aviram A (1982) Use of zinc iodide solutions in flow research. Rev Sci Instr 53(1)

Hopkins LM, Kelly JT, Wexler AS, Prasad AK (2000) Particle image velocimetry measurements in complex geometries. Exp Fluids 29(1):91-95

Horvay M, Leuckel W (1984) LDA measurement of liquid swirl flow in converging swirl chamber with tangential inlets. In: Proceedings of 2 nd international symposium on application of LDA to fluid mechanics, Lisbon

Hurlburt C (1984) The jewler's refractometer as a mineralogical tool. Am Mineral 69:391-398

Jacobs DA, Jacobs CW, Andereck CD (1988) Biological scattering particles for laser doppler velocimetry. Phys Fluids 31(12): 3457-3461

Jana SC, Kapoor B, Acrivos A (1995) Apparent wall slip velocity coefficients in concentrated suspensions of noncolloidal particles. J Rheol 39(6):1123-1132

Johnston W, Dybbs A, Edwards R (1975) Measurement of fluid velocity inside porous media with a laser anemometer. Phys Fluids 18(7):913-914

Kadambi JR, Chen RC, Bhunia S, Dybbs AZ, Edwards RV, Rutstein A (1990) Measurement of solid-liquid multiphase flow using refractive-index matching technique. In: Laser anemometryadvances and applications, pp 477-487

Kannemans H (1979) Principles of lda measurements in a fully transparent pump. In: Fluid mechanics silver jubilee conference, Glasgow

Kapoor B, Acrivos A (1995) Sedimentation and sediment flow in settling tanks with inclined walls. J Fluid Mech Digit Arch 290(1):39-66

Karnis A, Goldsmith HL, Mason SG (1966) The kinetics of flowing dispersions: I. concentrated suspensions of rigid particles. J Colloid Interface Sci 22(6):531-553

Kaufman LJ, Weitz DA (2006) Direct imaging of repulsive and attractive colloidal glasses. J Chem Phys 125(7):074716
Kegel WK, van Blaaderen A (2000) Direct observation of dynamical heterogeneities in colloidal hard-sphere suspensions. Science 287(5451):290-293

Kodak (2005) Kodak KAI-2020/KAI-2001 CCD timing specification version 1.1 evaluation board kit $4 \mathrm{~h} 0691$

Koh C (1991) Experimental and theoretical studies on two-phase fows. PhD thesis, California Institute of Technology

Koh C, Hookham P, Leal L (1994) An experimental investigation of concentrated suspension flows in a rectangular channel. J Fluid Mech 266:1-32

Kohnen C, Bohnet M (2001) Measurement and simulation of fluid flow in agitated solid/liquid suspensions. Chem Eng Technol 24(6):639-643

Krishnan GP, Beimfohr S, Leighton DT (1996) Shear-induced radial segregation in bidisperse suspensions. J Fluid Mech Digit Arch 321(1):371-393

Kubo K, Aratani T, Mishima A, Yano T (1978) Photographic observation of flow pattern in voids of packed-bed of spheres. J Chem Eng Jpn 11(5):405-407

Lam SY, Damzen MJ (2003) Characterisation of solid-state dyes and their use as tunable laser amplifiers. Appl Phys B Lasers Optics 77(6):577-584. doi:10.1007/s00340-003-1285-5

Leighton D, Acrivos A (1987) Measurement of shear-induced selfdiffusion in concentrated suspensions of spheres. J Fluid Mech 177:109-131

Lenoble M (2005) Ecoulement et ségrégation dans des pâtes granulaires modèle. $\mathrm{PhD}$ thesis, Université Bordeaux 1

Lenoble M, Snabre P, Pouligny B (2005) The flow of very concentrated slurry in a parallel-plate device: influence of gravity. Phys Fluids 17:073,303

Lenoble M, Snabre P, Pouligny B (2005b) Shearing a granular pate in a couette device: flow and size segraegation. In: Powders and grains, pp 621-624

Liu CH, Nouri JM, Whitelaw JH, Tse DGN (1989) Particle velocities in a swirling, confined flow. Combust Sci Technol 68(4-6):131-145

Liu CH, Vafidis C, Whitelaw JH, Margary R (1990) Flow in the coolant passages of an internal combustion engine cylinder head. Exp Fluids 10(1):50-54

Lorentz HA (1906) Theory of electrons. Teubner, Leipzig

Lyon M, Leal L (1998) An experimental study of the motion of concentrated suspensions in two-dimensional channel flow. part 1. monodisperse systems. J Fluid Mech 363:25-56

Lyon M, Leal L (1998) An experimental study of the motion of concentrated suspensions in two-dimensional channel flow. part 2. bidisperse systems. J Fluid Mech 363:57-77

McDougall TJ (1979) On the elimination of refractive-index variations in turbulent density-stratified liquid flows. J Fluid Mech Digit Arch 93(1):83-96

Mehta M, Kadambi JR, Sastry S, Sankovic JM, Wernet MP, Addie G, Visintainer R (2007) Particle velocities in the rotating impeller of a slurry pump. In: Fedsm 2007: Proceedings of the 5th joint AMSE/JSME fluids engineering summer conference, vol 1, pp 369-378

Mewis J, Wagner NJ (2009) Current trends in suspension rheology. J Non-Newton Fluid Mech 157(3):147-150

Mikami F, Chen B, Nishikawa N (1997) Visualization of the flow features of natural convection in particle suspensions. Theor Appl Mech 46:341-348

Mikami F, Chen B, Nishikawa N (2001) Visualization and PTV study of natural convection in particle suspensions (simultaneous measurements of velocity, temperature and interface between particle-free fluid and suspension). JSME Int J Ser B Fluids Therm Eng 44(1):30-37

Milliken WJ, Gottlieb M, Graham AL, Mondy LA, Powell RL (1989) The viscosity-volume fraction relation for suspensions of rod- 
like particles by falling-ball rheometry. J Fluid Mech Digit Arch 202(1):217-232

Mondy LA, Graham AL, Majumdar A, Bryant LE (1986) Techniques of measuring particle motions in concentrated suspensions. Int $\mathrm{J}$ Multiph Flow 12(3):497-502

Montemagno CD, Gray WG (1995) Photoluminescent volumetric imaging: a technique for the exploration of multiphase flow and transport in porous media. Geophys Res Lett 22

Moroni M, Cushman JH (2001) Three-dimensional particle tracking velocimetry studies of the transition from pore dispersion to fickian dispersion for homogeneous porous media. Water Resour Res 37

Narrow TL, Yoda M, Abdel-Khalik SI (2000) A simple model for the refractive index of sodium iodide aqueous solutions. Exp Fluids 28(3):282-283

Nguyen TT, Biadillah Y, Mongrain R, Brunette J, Tardif JC, Bertrand OF (2004) A method for matching the refractive index and kinematic viscosity of a blood analog for flow visualization in hydraulic cardiovascular models. J Biomech Eng 126(4): 529-535

Nicolai H, Guazzelli E (1995) Effect of the vessel size on the hydrodynamic diffusion of sedimenting spheres. Phys Fluids $7(1): 3-5$

Nicolai H, Herzhaft B, Hinch EJ, Oger L, Guazzelli E (1995) Particle velocity fluctuations and hydrodynamic self-diffusion of sedimenting non-brownian spheres. Phys Fluids 7(1):12-23

Nicolai H, Peysson Y, Guazzelli E (1996) Velocity fluctuations of a heavy sphere falling through a sedimenting suspension. Phys Fluids 8(4):855-862

Ninomiya N, Yasuda K (2006) Visualization and piv measurement of the flow around and inside of a falling droplet. $\mathrm{J}$ Vis 9(3):257-264

Northrup MA, Kulp TJ, Angel SM (1991) Application of fluorescent particle imaging to measuring flow in complex media. Anal Chim Acta 255(2):275-282

Northrup MA, Kulp TJ, Angel SM (1991) Fluorescent particle image velocimetry-application to flow measurement in refractive index-matched porous-media. Appl Optics 30(21):3034-3040

Northrup MA, Kulp TJ, Angel SM, Pinder GF (1993) Direct measurement of interstitial velocity-field variations in a porous-medium using fluorescent-particle image velocimetry. Chem Eng Sci 48(1):13-21

Nouri J, Whitelaw J, Yianneskis M (1986) An investigation of refractive-index matching of continuous and discontinuous phases. In: 3rd International symposium on applications of laser anemometry to fluid mechanics

Nouri JM, Whitelaw JH, Yianneskis M (1987) Particle motion and turbulence in dense two-phase flows. Int $\mathrm{J}$ Multiph Flow 13(6):729-739

Nouri J, Whitelaw J, Yianneskis M (1988) A refractive-index matching technique for solid/liquid flows. In: Laser anemometry in fluid mechanics, selected papers from the 3rd international symposium on application of laser-doppler anemometry to fluid mechanics

Oki Y, Yoshiura T, Chisaki Y, Maeda M (2002) Fabrication of a distributed-feedback dye laser with a grating structure in its plastic waveguide. Appl Optics 41(24):5030-5035

Okumura M, Yuki K, Hashizume H, Sagara A (2005) Evaluation of flow structure in packed-bed tube by visualization experiment. Fusion Sci Technol 47(4):1089-1093

Oster G, Yamamoto M (1963) Density gradient techniques. Chem Rev 63(3):257

Ouriev B (2000) Ultrasound doppler based in-line rheometry of highly concentrated suspensions. PhD thesis, ETHZ

Ouriev B (2002) Investigation of the wall slip effect in highly concentrated disperse systems by means of non-invasive uvp-pd method in the pressure driven shear flow. Colloid $\mathrm{J}$ 64(6):740-745

Ovarlez G, Bertrand F, Rodts S (2006) Local determination of the constitutive law of a dense suspension of noncolloidal particles through magnetic resonance imaging. J Rheol 50(3):259-292

Park JT, Mannheimer RJ, Grimley TA, Morrow TB (1989) Pipe flow measurements of a transparent non-newtonian slurry. J Fluids Eng Trans ASME 111(3):331-336

Parker J, Merati P (1996) An investigation of turbulent taylor-couette flow using laser doppler velocimetry in a refractive index matched facility. J Fluids Eng Trans ASME 118(4):810-818

Peurrung LM, Rashidi M, Kulp TJ (1995) Measurement of porous medium velocity fields and their volumetric averaging characteristics using particle tracking velocimetry. Chem Eng Sci 50(14):2243-2253

Plantard G, Saadaoui H, Snabre P, Pouligny B (2006) Surfaceroughness-driven segregation in a granular slurry under shear. Europhys Lett 75(2):335

Potanin A (2010) 3D simulations of the flow of thixotropic fluids, in a large-gap Couette and vane-cup geometries. J Nonnewton Fluid Mech 165:299-312

Raman C (1949) The theory of the christiansen experiment. Proc Indian Natl Sci Acad 29:381-390

Rashidi M, Peurrung L, Tompson AFB, Kulp TJ (1996) Experimental analysis of pore-scale flow and transport in porous media. Adv Water Resour 19(3):163-180

Russel J (1936) Studies of thixotropic gelation. part II. The coagulation of clay suspensions. Proc R Soc Lond A 154:550 560

Saleh S, Thovert JF, Adler PM (1992) Measurement of twodimensional velocity fields in porous media by particle image displacement velocimetry. Exp Fluids 12(3):210-212

Saleh S, Thovert J, Adler P (1993) Flow along porous media by partical image velocimetry. AIChE J 39(11):1765-1776

Savarmand S, Heniche M, Béchard V, Bertrand F, Carreau P (2007) Analysis of the vane rheometer using 3D finite element simulation. J Rheol 51:161-177

Shauly A, Averbakh A, Nir A, Semiat R (1997) Slow viscous flows of highly concentrated suspensions-part II: particle migration, velocity and concentration profiles in rectangular ducts. Int $\mathrm{J}$ Multiph Flow 23(4):613-629

Shindo Y, Kusano K (1979) Densities and refractive indices of aqueous mixtures of alkoxy alcohols. J Chem Eng Data 24(2):106-110

Shuib A, Hoskins P, Easson W (2010) Flow regime characterization in a diseased artery model. World Acad Sci Eng Technol 62:110

Sinkankas J (1966) Mineralogy. D Van Nostrand Company, Princeton, pp 226-233

Stähr M, Roth K, JShne B (2003) Measurement of 3d pore-scale flow in index-matched porous media. Exp Fluids 35(2):159-166

Stephenson JL, Stewart WE (1986) Optical measurements of porosity and fluid motion in packed beds. Chem Eng Sci 41(8): 2161-2170

Sveen J (2004) An introduction to matpiv (http://www.folk.uio. no/jks/matpiv/)

Tanaka M (1999) Visualization of flow in a cubic packing of spheres. In: 9th International topical meeting on nuclear reactor thermal hydraulics, San Fransisco

Tasic AZ, Djordjevic BD, Grozdanic DK, Radojkovic N (1992) Use of mixing rules in predicting refractive indexes and specific refractivities for some binary liquid mixtures. J Chem Eng Data 37(3):310-313

Thompson BE (1990) Refractive index matching techniques in complex rocket-engine flow configurations. Technical report

Timberlake B, Morris J (2002) Concentration band dynamics in freesurface couette flow of a suspension. Phys Fluids 14:1580-1589 
Tung LH (1956) Correction. J Polym Sci 19(93):598

Tung LH, Taylor WC (1955) A rapid method of constructing density gradient tubes. J Polym Sci 17(85):441-442

Tung LH, Taylor WC (1956) An improved method of preparing density gradient tubes. J Polym Sci 21(97):144-147

Uzol O, Chow YC, Katz J, Meneveau C (2002) Unobstructed particle image velocimetry measurements within an axial turbo-pump using liquid and blades with matched refractive indices. Exp Fluids 33(6):909-919

Van De Hulst HC (1957) Light scattering by small particles. Wiley, New York

Varty RL (1984) A new system for index-matched laser-anemometer measurements. J Phys E Sci Instr 17(12):1124-1126

Walters K (1975) Rheometry. Chapman and Hall, London

Wang DC, Khalili A (2002) Flow visualization and quantitative measurements inside porous media by particle image velocimetry. Opt Technol Image Process Fluids Solids Diagn 5058:232-239

Wang P, Song C, Briscoe C, Makse HA (2008) Particle dynamics and effective temperature of jammed granular matter in a slowly sheared three-dimensional couette cell. Phys Rev E 77(6): 061309

Waxler R, Horowitz D, Feldman A (1979) Optical and physical parameters of plexiglay 55 and lexan. Appl Opt 18:101

Weeks ER, Crocker JC, Levitt AC, Schofield A, Weitz DA (2000) Three-dimensional direct imaging of structural relaxation near the colloidal glass transition. Science 287(5453):627-631
Wiederseiner S (2010) Rheophysics of concentrated particle suspensions in a couette cell using a refractive index matching technique. $\mathrm{PhD}$ thesis, Ecole Polytechnique fédérale de Lausanne

Wiener O (1910) Leipzig Ber 62:256

Wildman DJ, Ekmann JM, Kadambi JR, Chen RC (1992) Study of the flow properties of slurries using the refractive index matching technique ldv. Powder Technol 73(3):211-218

Yarlagadda A, Yoganathan A (1989) Experimental studies of model porous media fluid dynamics. Exp Fluids 8(1):59-71

Yianneskis M, Whitelaw J (1983) Velocity characteristics of pipe and jet flow witch high particle concentrations. Technical report FS/ 83/22, Imperial College

Yuki K, Okurnura M, Hashizume H, Toda S, Morley NB, Sagara A (2008) Flow visualization and heat transfer characteristics for sphere-packed pipes. J Thermophys Heat Transf 22(4):632-648

Zachos A, Kaiser M, Merzkirch W (1996) PIV measurements in multiphase flow with nominally high concentration of the solid phase. Exp Fluids 20(3):229-231

Zerai B, Saylor BZ, Kadambi JR, Oliver MJ, Mazaheri AR, Ahmadi G, Bromhal GS, Smith DH (2005) Flow characterization through a network cell using particle image velocimetry. Transp Porous Media 60:159-181

Zisselmar R, Molerus O (1979) Investigation of solid-liquid pipe flow with regard to turbulence modification. Chem Eng J 18(2):233-239 